Research paper

\title{
Therapeutic potential for coxibs-nitric oxide releasing hybrids in cystic fibrosis
}

\author{
Sara Consalvi a , Giovanna Poce ${ }^{a}$, Carla Ghelardini ${ }^{b}$, Lorenzo Di Cesare Mannelli ${ }^{\text {b }}$, \\ Paola Patrignani ${ }^{\mathrm{c}}$, Annalisa Bruno ${ }^{\mathrm{c}}$, Maurizio Anzini ${ }^{\mathrm{d}}$, Vincenzo Calderone ${ }^{\mathrm{e}}$, \\ Alma Martelli ${ }^{\mathrm{e}}$, Lara Testai ${ }^{\mathrm{e}}$, Antonio Giordani ${ }^{\mathrm{f}}$, Mariangela Biava ${ }^{\mathrm{a}, *}$ \\ a Department of Chemistry and Technologies of Drug, Sapienza University of Rome, Piazzale A. Moro 5, 00185, Rome, Italy \\ b Department of Neuroscience, Psychology, Drug Research and Child Health, University of Florence, Via Schiff 6, Sesto Fiorentino, 50019, Florence, Italy \\ ' Department of Neuroscience, Imaging and Clinical Sciences, And Center for Advanced Studies and Technology (CAST), School of Medicine, G. D'Annunzio \\ University, Chieti, Italy \\ d Department of Biotechnology, Chemistry, And Pharmacy, DoE 2018-2022, University of Siena, 53100, Siena, Italy \\ e Department of Pharmacy, University of Pisa, Via Bonanno 6, 56126, Pisa, Italy \\ ${ }^{\mathrm{f}}$ Formerly Rottapharm at the Present Consultant, Italy
}

\section{A R T I C L E I N F O}

\section{Article history:}

Received 4 June 2020

Received in revised form

27 October 2020

Accepted 28 October 2020

\section{Keywords:}

Cystic fibrosis

Inflammation

CINODs

COX-2

\begin{abstract}
A B S T R A C T
This review discusses the rational for further studies of COX-2 inhibitors-NO releaser hybrids (NOCoxibs) in the pharmacological treatment of the airway inflammation in Cystic Fibrosis (CF). Our research group developed several classes of NO-Coxibs for the pharmacological treatment of arthritis, and among them several compounds showed an outstanding in vivo efficacy and good pharmacokinetic properties. The good antiinflammatory properties displayed by these compounds during the previous screening could, by itself, suggest appropriate candidates for further testing in CF.
\end{abstract}

(c) 2020 Elsevier Masson SAS. All rights reserved.

\section{Introduction}

Cystic fibrosis (CF) is one of the most common genetic inherited life-shortening disease affecting Caucasian population. It is caused by mutations in the gene of the cystic fibrosis transmembrane regulator (CFTR), a cAMP-dependent anion channel mostly expressed in the apical membrane of epithelia cells [1,2]. Therefore, the primary defect in CF patients is a reduction in chloride and bicarbonate transport capacity across the apical membrane of epithelial cells, which in turn impacts on water secretion and sodium concentration, altering the characteristics of the secreted fluids [3]. The most common CFTR mutation found in CF patients is F508CFTRdel. This deletion results in a loss of the phenylalanine at position 508 of the protein, which prevents the protein from folding efficiently and affects the function and processing of the CFTR molecules [4]. Although, the shortened life expectancy

\footnotetext{
* Corresponding author.

E-mail address: mariangela.biava@uniroma1.it (M. Biava).
}

accompanying the disease can most often be attributed to pulmonary complications [5], patients with CF also suffer from a variety of systemic complications including dysfunction of the gastrointestinal (pancreas and liver), renal, immune, endocrine and male genital systems [6,7]. In the lungs CFTR dysfunction is associated with loss of the critical hydration of the airway surface, abnormal mucin secretion, epithelial cell vulnerability and with dysregulation of the local inflammatory responses, resulting in excessive airway neutrophilic inflammation and pathogen growth [8]. The resulting dysregulation of defence function followed by persistent bacterial infections gives rise to airway damage and remodelling, leading to severe lung deficiency $[9,10]$.

\subsection{Inflammation in $C F$}

In the past, the combination of mucus obstruction and infection was believed to drive the exaggerated and dysfunctional inflammatory response, which leads to irreversible airway destruction and fibrosis and hence to severe lung damage, the main cause of morbidity and mortality in CF patients. More recently, it has been 


$\begin{array}{ll}\text { Abbreviations } \\ \text { CF } & \text { cystic fibrosis } \\ \text { CFTR } & \text { cystic fibrosis transmembrane regulator } \\ \text { CINODs } & \text { COX-inhibiting nitric oxide donors } \\ \text { COX } & \text { cyclooxygenase } \\ \text { CV } & \text { cardiovascular } \\ \text { GSNO } & \text { S-nitrosoglutathione } \\ \text { GI } & \text { gastrointestinal } \\ \text { LPS } & \text { lipopolysaccharide } \\ \text { NO } & \text { nitric oxide } \\ \text { NOS } & \text { nitric oxide synthase } \\ \text { NOBA } & \text { 4-(nitroxy) butanol }\end{array}$
NO-coxibs NO-releasing coxibs
NSAIDs nonsteroidal anti-inflammatory drugs
ODQ 1H-[1,2,4]-oxadiazole[4,3-a] quinoxalin-1-one
PGH2 prostaglandin $\mathrm{H} 2$
$\mathrm{PGI}_{2} \quad$ prostacyclin 2
PBS phosphate buffered saline
SAR structure-activity relationships
SBP systolic blood pressure
SGF simulated gastric fluid
SHRs spontaneous hypertensive rats
SNOs S-nitrosothiols
$t$-NSAIDs traditional-NSAIDs
WHB whole human blood

shown that neutrophilic inflammation is already present in young children with $\mathrm{CF}$, even in the absence of respiratory infections, suggesting that the disease itself might be related to anomalous inflammatory responses [11]. Moreover, it has been reported how CFTR defects in CF contribute to endogenous activation of NF-kB, and to the exaggerated production of the pro-inflammatory cytokines IL- $1 \beta$, IL-6, IL- 8 and TNF- $\alpha$, even in the absence of bacterial infections [12-14]. In addition to increased release of proinflammatory cytokines, it was also demonstrated an overproduction of $\mathrm{PGE}_{2}$ and other prostanoids in patients with CF [15]. Cyclooxygenase (COX) represents the key enzyme in arachidonic acid metabolism, converting arachidonic acid to prostaglandin $\mathrm{H} 2$ (PGH2). COX consists of two isoforms: COX-1 and COX-2. The constitutively expressed COX-1 exerts housekeeping functions in most tissues maintaining the homeostasis. Inhibition of COX-1 reduces platelet thromboxane $\mathrm{B}_{2}$ and $\mathrm{PGE}_{2}$ production in several tissues. Even though COX-1 may contribute to the total pool of prostaglandins at the site of inflammation, its contribution to inflammation is at the present not fully understood. Conversely, COX-2 is induced, in response to inflammatory cytokines, in various cell types (including monocytes/macrophages). Since this isoform is notably activated by pro-inflammatory stimuli and presents mainly a pro-inflammatory function, it was highlighted as the most important player in inflammatory processes. COX-2 is considered the main target for NF-kB activation, a key factor in the dysregulation of the innate immune and host inflammatory response [16]. It is well known how the mutations in CFTR influence the lung epithelial innate immune function leading to exaggerated and ineffective airway inflammation that fails to abolish pulmonary pathogens and gives rise to structural damage of the airways impairing lung function and ultimate leading to respiratory failure and death [10]. It was recently shown, how the reduction of COX protein levels (mainly COX-2) had a positive effect on all analysed clinical parameters. This suggests an important role of the inhibition of arachidonic acid conversion into prostaglandins which, by reducing the inflammatory process, acts as protective modifier of pulmonary disease in CF patients [17,18].

With the recognition that airway inflammation plays a significant pathogenic role in $\mathrm{CF}$, modulation of the inflammatory response has become a significant therapeutic target and drugs that target inflammation have been shown to slow the decline in lung function and improve survival $[19,20]$. Corticosteroid administration showed positive effects on lung function; however, the accompanying adverse effects led to premature discontinuation of clinical trials. Ibuprofen, a COX-1/COX-2 inhibitor, is the only antiinflammatory drug currently recommended for the long-term treatment of CF airway inflammation [21]. In animal models of chronic infection, high-dose ibuprofen was demonstrated to reduce inflammation without hindering bacterial clearance. This led to clinical trials which demonstrated a benefit in slowing the progression of lung disease in CF. However, concerns about adverse effects have limited the use of high-dose ibuprofen in CF patients. Interestingly, it was observed that ibuprofen at the high clinically relevant doses can suppress transcriptional activity of $\mathrm{NF}-\kappa \mathrm{B}$ and other pro-inflammatory transcription factors [22]. High-dose ibuprofen can also enhance the function of F508delCFTR and it corrects CFTR function [23].

\subsection{CFTR correctors and potentiators}

In addition to therapeutics that have been developed to treat the symptoms of $\mathrm{CF}$, more recent research has been focused on the development of therapies targeting the root cause of $\mathrm{CF}$, identifying suitable compounds that could reverse the CFTR molecular defect and prevent the progression of CF disease [24]. Recent studies have revealed that inhibition of F508delCFTR ubiquitination and proteasomal degradation with chemical or pharmacological chaperones promotes its correct folding and channel function. Thus, pharmacological strategies that increase the maturation of the mutant CFTR (correctors) [25] and/or potentiate channel conductance (potentiator) [26] should be beneficial to the majority of $\mathrm{CF}$ patients. The knowledge of the CFTR molecular target, the development of appropriate pharmacological tests along with highthroughput screening led to the success in partial pharmacologic restoration of CFTR activity. However, the currently available clinical data suggest that this therapy will require combinations of CFTR correctors and potentiator exploiting different mechanisms of action with additive/synergistic efficacies. A few small molecules targeting mutant CFTR are available for CF patients: lumacaftor (VX-809) (corrector) and ivacaftor (VX-770) (potentiator) along with the corresponding combination therapy [27,28]. Unwanted side effects and drug interactions of lumacaftor have recently been overcame with the development of tezacaftor (VX-661) $[29,30]$. Recently, a triple combination of two correctors, elexacaftor (VX445) and tezacaftor, and a potentiator (ivacaftor) has been approved for the treatment of CF patients carrying the F508delCFTR mutation [31-33]. Despite these progresses many CF patients still await more effective drug treatments [34].

\subsection{Nitric oxide and $C F$}

Nitric Oxide (NO), formed from L-arginine by NO synthases (NOS-1,2,3) has been shown to play an essential role in a variety of biological processes in the lung, including bronchodilation, inflammation and host-defence against pathogens [35-37]. NOS1 derived NO is a neurotransmitter and is involved in human 
bronchomotor control. Its anomalous activity contributes to the development of airway obstruction. In the lung NOS2 is expressed by macrophages, neutrophils and bronchial epithelial cells and manly acts as antimicrobial agent. NOS3 is constitutively expressed in pulmonary blood vessels, airway epithelial cells and neutrophils. There is increasing evidence that NOS3 contributes to NO related patho-physiology in the airways [38].

Although NO concentration in exhaled air is generally increased in inflammatory lung diseases like asthma and bronchiectasis, in CF patients it is not increased, or even decreased. Moreover, in upper airways NO is significantly lower in CF patients than in controls [39]. The reasons for this NO deficiency may include reduced expression of NOS, as well as lower availability of L-arginine [40]. Therapeutic interventions aiming at correcting the NO deficiency in CF patients are therefore currently being explored as new therapies for this disease. A clinical study assessing the safety and efficacy of inhaled NO as adjuvant therapy in CF patients was reported [41]. However, the hazards of pressurized cylinders and toxicity concerns have led researchers to develop and study the utility of NO donors. For example, the cephalosporin (NO)-donor prodrug DEAC3D designed to deliver NO to bacterial infection sites, selectively releases NO in response to contact with bacterial $\beta$-lactamase [42]. Several carbonic anhydrase inhibitors NO-donors have shown good ability in reducing elevated intraocular pressure in an animal model of ocular hypertension for the treatment of glaucoma [43-45]. Alginate biopolymers can be chemically modified to store and release NO. The resulting $\mathrm{N}$-diazenium diolate alginate NO donors showed in aqueous solution NO-release kinetics able to produce therapeutic NO levels. In particular, the generated NO showed bactericidal activity against Pseudomonas aeruginosa and Staphylococcus aureus and other strains relevant to CF [46,47]. S-nitrosothiols (SNOs), which can be formed by reaction of NO with thiols, are endogenous cell signalling molecules present in the lung [48-50]. Despite the physiological importance, low concentrations of SNOs were found in CF patients [51]. It was reported that Snitrosoglutathione (GSNO) increases cellular expression, maturation, and function of CFTR in human airway epithelial cell cultures expressing mutant F508del CFTR [52]. These actions reflect in a clinical efficacy in CF patients treated with GSNO [53,54]. More recently, it was reported how this effect is common also with other SNOs [55]. Therefore, the ability of SNOs to augment the maturation and stability of the CFTR could be helpful on the treatment of CF, and there is growing interest in more bioavailable and stable NOSs compounds or corresponding precursors as a novel class of corrector therapies for CF (Fig. 1).

\subsection{COX-inhibiting nitric oxide donors (CINODs)}

Among all the mediators participating in the inflammation process, prostaglandins remain the major target of antiinflammatory therapies since nonsteroidal anti-inflammatory drugs (NSAIDs) have been discovered. NSAIDs are also widely used to treat the inflammatory pain and act by inhibiting COX isoforms. As discussed in paragraph 1.2, the COX isoforms catalyse the conversion of arachidonic acid to prostanoids, but with differences in terms of expression, function and structure. The constitutively expressed COX-1 exerts housekeeping functions in most tissues maintaining the homeostasis. It is also important for gastric cytoprotection. COX-2 is induced in response to inflammatory cytokines giving rise to a massive release of $\mathrm{PGE}_{2}$, and it is the main player in inflammation. However, COX-2 is also constitutively expressed in some tissues (e.g. kidney, endothelial cells and brain) where its products $\mathrm{PGE}_{2}$ and prostacyclin $\left(\mathrm{PGI}_{2}\right)$ are involved in diverse physiological functions including renal haemodynamic and the control of blood pressure along with endothelial thromboresistance. COX-1 and COX-2 enzymes share about 60\% sequence identity and are characterized by similar three-dimensional structures. However, the COX active sites are not identical, the COX-2 binding site is more flexible and 25\% larger than the one of COX1 , with a side-pocket not present in the COX-1 isoform. These differences in the binding site size and structure enable to develop ligands "selective" for COX-2. All NSAIDs can inhibit COX-1 and COX-2 in a concentration-dependent fashion. The ratio between the $50 \%$ inhibitory concentration $\left(\mathrm{IC}_{50}\right)$ values for COX-1 and COX-2 is used to describe the COX-2 selectivity of these drugs and to characterize selective vs. nonselective inhibitors. The selective COX-2 inhibitors have been named coxibs while COX inhibitors with scanty selectivity for COX-2 are referred to as traditional-NSAIDs ( $t$ NSAIDs). Therapy with $t$-NSAIDs is hampered by some side-effects including gastrointestinal erosions and renal insufficiency. Such critical adverse reactions are mostly dependent on COX-1 inhibition [56]. Due to its main pro-inflammatory function, COX-2 was

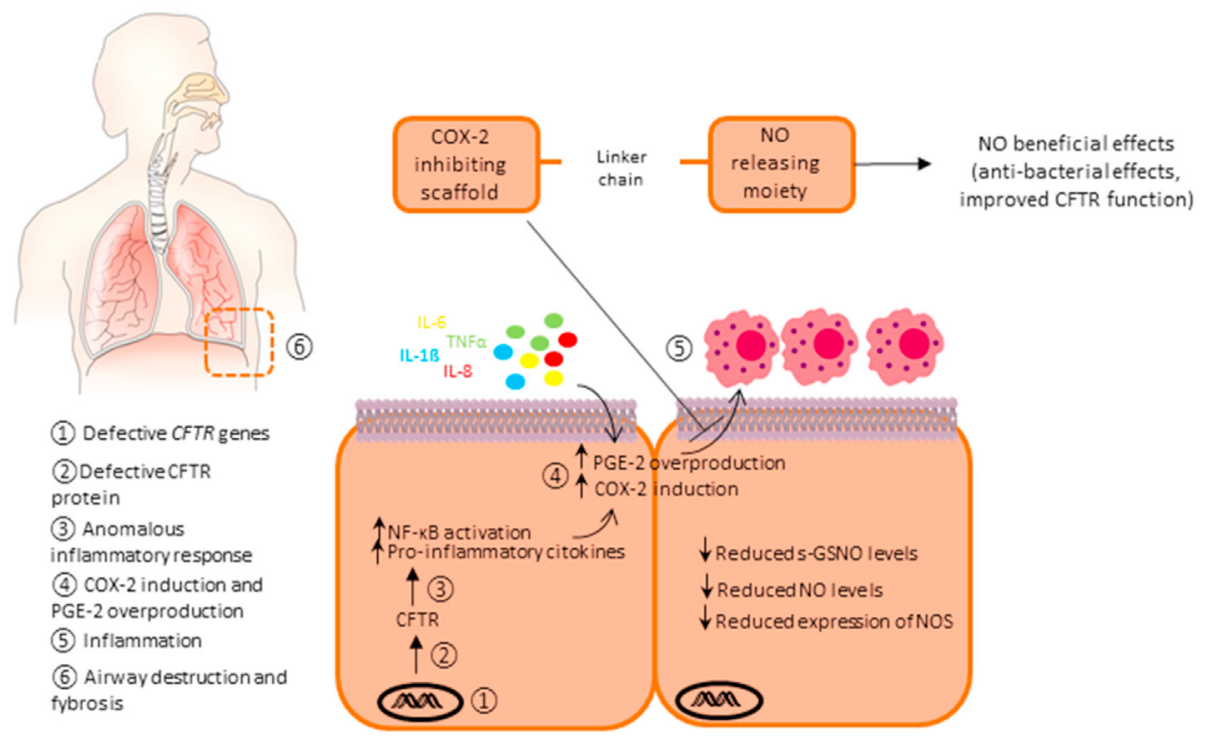

Fig. 1. Perspective on the rationale of using NO-Coxibs in Cystic Fibrosis. 
highlighted as a suitable target for treating inflammation, possibly without gastrointestinal (GI) side-effects [57]. Consequently, coxibs were developed to overcome the GI and renal side effects associated with the use of $t$-NSAIDs [58]. Later on, numerous studies of clinical pharmacology and pharmacoepidemiology showed that preferential inhibition of COX-2 translates into a cardiovascular (CV) hazard [59]. The pattern of the cardiovascular effects of COX-2 inhibitors is consistent with the increased risk of coronary events being related to a diminished restraining effect of endothelial $\mathrm{PGI}_{2}$ on platelet activation, as suggested by in-depth studies of experimental thrombogenesis in COX-2-deficient mice [60]. This CV hazard is shared with $t$-NSAIDs through the same mechanism and it is more relevant as more is pronounced the preference for COX-2 inhibition of the drug [61].

COX-inhibiting nitric oxide donors (CINODs) was a class of drugs initially developed to combine the pharmacological actions of a COX inhibitor with the protective actions of NO, with the aim of reducing the GI toxicity of the drug, while maintaining its analgesic and antiinflammatory effects. Naproxcinod (AZD3582) was the first in class of this group of compounds formerly developed by NicOx [62]. As NO is endowed with remarkable CV protective actions, being involved in vascular smooth muscle relaxation, platelet aggregation and thrombosis inhibition, it was speculated that NSAIDs endowed with NO-releasing properties could also mitigate the corresponding CV hazard. Aiming to design COX-2 selective inhibitors with improved CV safety, NO releasing coxibs have been synthesised, in order to compensate for the COX-2 effects on prostacyclin with NO-mediated $\mathrm{CV}$ effects. Our past research has been focused on the development of a new class of potent and selective coxibs based on the diarylpyrrole scaffold [63-65]. Later on, we developed a class of NO-releasing coxibs (NO-coxibs) endowed with anti-inflammatory properties and characterized by a better cardiovascular safety profile, due to NO antithrombotic and cardioprotective effects [66-68]. The pharmacokinetic of the compounds and the NO releasing properties were also optimized in order to provide compounds with the appropriate duration of action along with slow NO releasing properties [69-71]. Within the same timeframe, an interesting NO-releasing prodrug of rofecoxib [72], was reported as well as nitroxy-substituted 1,5diarylimidazoles [73] and corresponding analogues of celecoxib [74]. In this review we discuss the rational for further studies of COX2 inhibitors-NO releaser hybrids (NO-Coxibs) in the pharmacological treatment of the airway inflammation in CF. Our research group developed several classes of NO-Coxibs for the pharmacological treatment of arthritis, and among them several compounds showed an outstanding in vivo efficacy and good pharmacokinetic properties. The good antiinflammatory properties displayed by these compounds during the previous screening could suggest, by itself, appropriate candidates for further testing in $\mathrm{CF}$.

\section{NO-coxibs based on diarylpyrrole scaffold: nitrooxyalkyl esters}

Due to their high COX-2 inhibitory potency and selectivity, 1,5- diarylpyrrole-3-acetic acid (1a-d) and esters (2a-m) (Fig. 2) were the starting point for this work. As structure-activity relationships (SAR) of these compounds was investigated in previous works [63-65], the substitution patterns on N1-phenyl that provided better results were selected for this study (representative substituents: H, 3-F, 4-F, 4-OMe) as well as the preference for the $p$ methylsulfonyl-phenyl moiety in the $\mathrm{C}-5$ position of the pyrrole ring. CINOD structures are characterized by a central core responsible for COX inhibition with a linked NO donating moiety. In particular, naproxcinod is the ester of naproxen with 4-(nitroxy) butanol (NOBA) (Fig. 2). Among the possible approaches for "hybridization" of our scaffold, the one consisting in the manipulation at position-3 of pyrrole nucleus, allowed us to retain COX-2 inhibitory properties and to introduce the NO-releasing moiety. Conversely, other scaffold manipulations led to the loss of COX-2 inhibition.

In order to test the pharmacological hypothesis of the study, the straightforward preparation of 1,5-diarylpyrrole-3-acetic nitrooxyalkyl esters (3a-h) (Table 1) [66] as NO-releasing hybrids was chosen. These compounds were designed by combining the 1,5diarylpyrrole moiety (compounds 1a-d) with NO-donor alkyl chains of different length, on the basis of previous molecular modelling considerations on different length and hindrance chains of analogue esters 2a-m [63]. Since the nitrooxyalkyl groups are metabolized in vivo, we also considered the corresponding hydroxyl derivatives $(\mathbf{4 a}-\mathbf{h})$ (Table 1$)$ as possible metabolites. All compounds herein described were evaluated for in vitro potency and selectivity for COX-1 and COX-2 inhibition in a J774 murine macrophage cell line. For selected compounds the human wholeblood assays (WHB) was used to assess COX-1/-2 activities and selectivity. This test is represented by WHB assay of COX isoforms activities that exploit the constitutive and lipopolysaccharide (LPS)inducible COX activities of circulating platelets and monocytes, as reflected by serum $\mathrm{TXB}_{2}$ and plasma $\mathrm{PGE}_{2}$ levels, respectively [66]. In order to evaluate NO-releasing properties the compounds were evaluated assessing their efficacy and potency in determining NOvasorelaxing responses, using a model of vascular smooth muscle relaxation (endothelium denuded rat aortic rings) [66]. In order to confirm that the vasorelaxing effects observed were actually due to the NO release, the experiments were also carried out in the presence of the guanylate cyclase inhibitor $1 \mathrm{H}-[1,2,4]$-oxadiazole [4,3-a] quinoxalin-1-one (ODQ). The time dependent determination of nitrate and nitrite formation by incubation with liver homogenate was assessed as well [67,70]. For selected compounds, in vivo anti-inflammatory and analgesic activities were evaluated in animal models of inflammation, using the chemical visceral inflammatory model (pain induced by the intraperitoneal injection of acetic acid, writhing test), and the carrageenan-induced inflammatory pain model [66]. Intraperitoneal injection of acetic acid induces abdominal irritation characterized by abdominal stretching, flinching, licking, and motor incoordination. The writhing response is due to the release of cytokines, prostaglandins, and bradykinin, factors capable of sensitizing visceral nociceptive

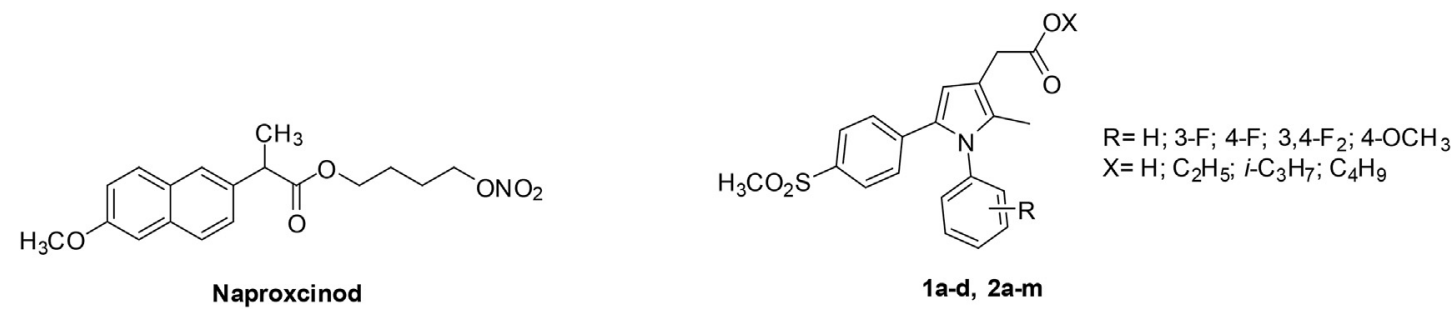

Fig. 2. Chemical structures of Naproxcinod and compounds $\mathbf{1 a - d}$ and $\mathbf{2 a - \mathbf { m }}$. 
Table 1

COX-1 and COX-2 inhibitory activity of $\mathbf{3 a}-\mathbf{h}, \mathbf{4 a}-\mathbf{h}$, and Celecoxib.

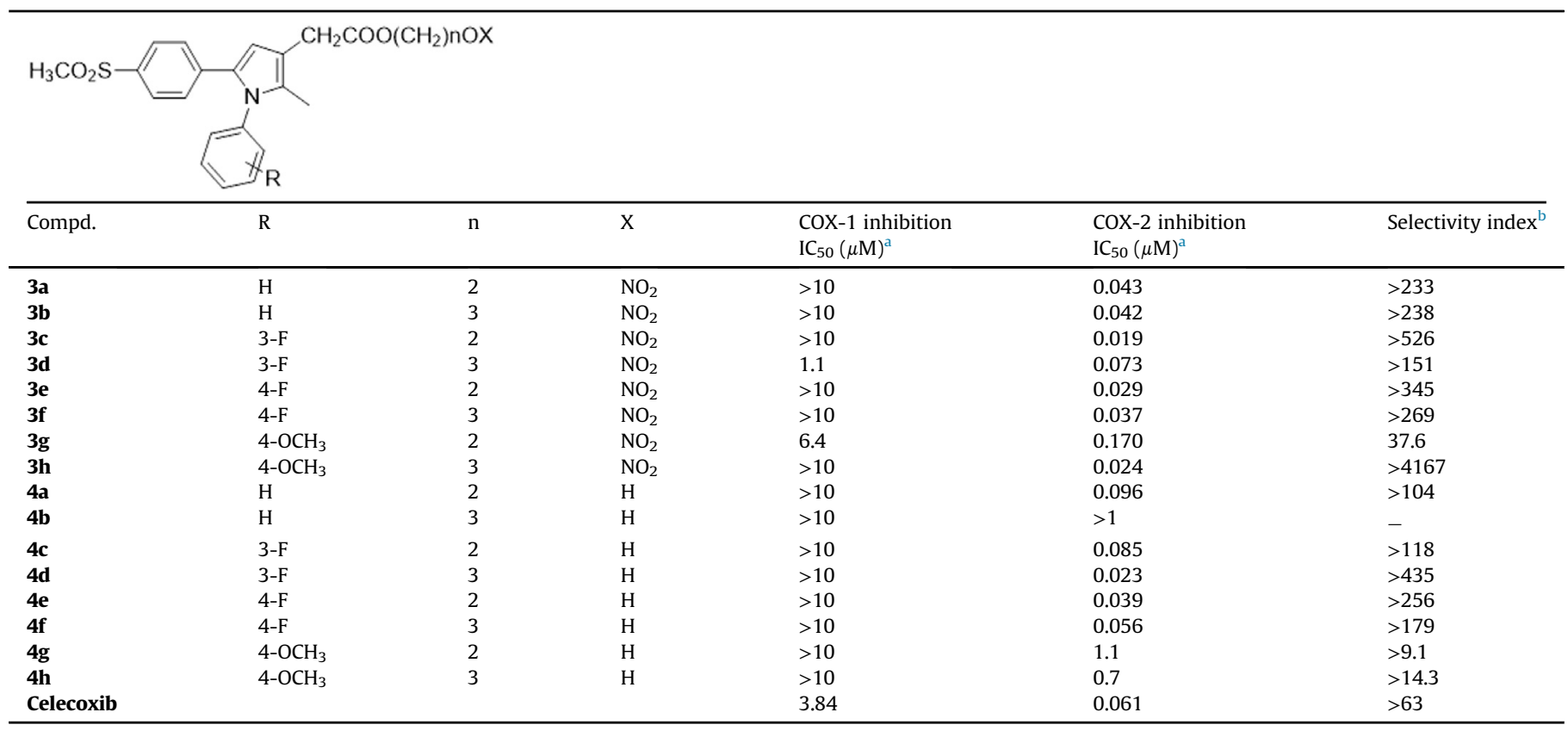

a Results are expressed as the mean ( $\mathrm{n}=3$ experiments) of the \% inhibition of $\mathrm{PGE}_{2}$ production by test compounds with respect to control samples and the IC $\mathrm{C}_{50}$ values were calculated by GraphPad Instat program; data fit was obtained using the sigmoidal dose-response equation (variable slope) (GraphPad software).

${ }^{\mathrm{b}}$ In vitro COX-2 Selectivity Index [ $\left.\mathrm{IC}_{50}(\mathrm{COX}-1) / \mathrm{IC}_{50}(\mathrm{COX}-2)\right]$.

afferents [75]. The carrageenan-induced inflammatory pain model is widely used to assess the anti-inflammatory activity of several compounds. Carrageenan is a non-antigenic phlogistic agent with the devoid of any visible systemic effects, it contains sulphated sugars that are liable for the activation of complement system and the inflammatory mediators [76]. Compounds $\mathbf{3 a - h}$ and $\mathbf{4 a - h}$ were then evaluated according to the above pharmacological protocol. Nitrooxyalkyl esters 3a-f and $\mathbf{3 h}$ resulted very active and selective COX-2 inhibitors (Table 1). They displayed better potencies and selectivity than corresponding acids 2a-g and esters 1a-g. Dependence on the side-chain length with the COX-2 inhibition potency was highlighted in this series. Hydroxylated derivatives $(\mathbf{4 a}-\mathbf{h})$ displayed a similar trend. The side-chain length seems to be crucial also in determining NO-dependent vasorelaxing responses. For compounds $\mathbf{3 a - h}$ strong vasorelaxing effects ( $\mathrm{pIC}_{50}$ ranging between 5.47 and 6.75) (Table 2) were found only for the two-carbon chain nitroesters (3a, 3c, 3e, 3g), while a weak activity characterized the three-carbon chain derivatives. The test with ODQ

Table 2

Efficacy and potency in determining NO-dependent vasorelaxing responses of $\mathbf{3 a}-\mathbf{h}$ and GTN ${ }^{\mathrm{a}}$.

\begin{tabular}{lllll}
\hline Compd. & $\mathrm{R}$ & $\mathrm{n}$ & $\mathrm{E}_{\max }{ }^{\mathrm{b}}$ & $\mathrm{pIC}_{50}{ }^{\mathrm{c}}$ \\
\hline 3a & $\mathrm{H}$ & 2 & $65 \pm 2$ & $5.76 \pm 0.08$ \\
3b & $\mathrm{H}$ & 3 & $44 \pm 8$ & $<5$ \\
3c & $3-\mathrm{F}$ & 2 & $69 \pm 4$ & $6.48 \pm 0.06$ \\
3d & $3-\mathrm{F}$ & 3 & $39 \pm 1$ & $<5$ \\
3e & $4-\mathrm{F}$ & 2 & $58 \pm 5$ & $5.47 \pm 0.07$ \\
3f & $4-\mathrm{F}$ & 3 & $41 \pm 2$ & $<5$ \\
3g & $4-\mathrm{OCH}_{3}$ & 2 & $77 \pm 2$ & $6.75 \pm 0.05$ \\
3h & $4-\mathrm{OCH}_{3}$ & 3 & $41 \pm 11$ & $<5$ \\
GTN & & & $73 \pm 2$ & $6.90 \pm 0.07$ \\
\hline
\end{tabular}

a GTN: glyceryl trinitrate.

b Emax represents the vasorelaxing efficacy, expressed as a \% of the vasoconstriction induced by the pre-administration of $\mathrm{KCl}$.

c Parameter of potency is expressed as $\mathrm{pIC}_{50}$, representing $-\log$ of the molar concentration capable of inducing a vasorelaxing effect $=50 \%$ of $\mathrm{E}_{\max }$. confirmed these vasorelaxing effects were due to the NO release. The total loss of vasorelaxing activity of the hydroxylated derivatives $\mathbf{4 a}-\mathbf{h}$ further supported the absence of contribution from other moieties of the molecule to the CV effect. Additional experiments suggested that these compounds ensured a slow NO release suitable for the expected pharmacological action [66]. The metafluorine subclass of compounds (3c-d) was selected for ex vivo and in vivo studies. The COX-2 selectivity was assessed ex vivo for derivatives $3 \mathbf{c}$ and the expected metabolite $4 \mathbf{c}$, by the HWB assay. Compounds $3 \mathbf{c}$ and $\mathbf{4 c}$ inhibited platelet COX-1 in a concentrationdependent fashion, with $\mathrm{IC}_{50}: 9.6 \mu \mathrm{M}$ and $12.2 \mu \mathrm{M}$ respectively. Compounds $\mathbf{3 c}$ and $\mathbf{4 c}$ displayed similar inhibitions of monocyte COX-2 with $\mathrm{IC}_{50}$ : $3.2 \mu \mathrm{M}$ and $1.7 \mu \mathrm{M}$, respectively (Celecoxib COX-1 $12.5 \mu \mathrm{M}$; COX-2 $0.54 \mu \mathrm{M})$. Thus, $3 \mathrm{c}$ was 3 -fold and $4 \mathrm{c}$ was 7.3 -fold more potent toward COX-2 than toward COX-1; the drop in COX2 potency and selectivity in HWB assay versus J774 model can be explained by the different sensitivities of mice and human COX

Table 3

Effect of 3c-d, 4c-d, Celecoxib, and vehicle (CMC) in the mouse abdominal constriction test (Acetic acid $0.6 \%$ ).

\begin{tabular}{llll}
\hline Compd. $^{\mathrm{a}}$ & No. mice & dose po, $\mathrm{mg} / \mathrm{kg}(\mu \mathrm{mol} / \mathrm{kg})^{b}$ & no. writhes \\
\hline CMC & 43 & - & $32.6 \pm 2.1$ \\
3c & 12 & $20(42)$ & $17.1 \pm 2.3^{*}$ \\
3c & 12 & $40(84)$ & $9.4 \pm 2.5^{*}$ \\
3d & 18 & $20(41)$ & $25.7 \pm 2 . \wedge^{*}$ \\
3d & 10 & $40(82)$ & $24.9 \pm 2.2^{*}$ \\
4c & 8 & $3(7)$ & $26.9 \pm 3.0^{*}$ \\
4c & 8 & $10(23)$ & $17.4 \pm 2.9^{*}$ \\
4c & 8 & $20(46)$ & $16.2 \pm 2.8^{*}$ \\
4c & 8 & $30(70)$ & $8.9 \pm 2.1^{*}$ \\
4d & 10 & $20(45)$ & $25.3 \pm 2.8$ \\
4d & 10 & $40(90)$ & $15.6 \pm 2.2^{*}$ \\
Celecoxib & 10 & $10(26)$ & $13.4 \pm 2.6^{*}$ \\
\hline
\end{tabular}

${ }^{b}$ Doses are expressed in $\mathrm{mg} / \mathrm{kg}$. The equivalent doses in $\mu \mathrm{mol} / \mathrm{kg}$ are indicated in parentheses. ${ }^{*}, P<0.01$ versus vehicle-treated mice. $\wedge, P<0.05$.

a All compounds were administered per os $30 \mathrm{~min}$ before test. 
enzymes. The writhing test confirmed the in vivo antiinflammatory activity for all the compounds tested (Table 3). Despite the higher in vitro potency, all the compounds were in vivo less potent than Celecoxib, though similar effects could be obtained at higher doses. Findings reported for carrageenan induced hyperalgesia and edema showed that all compounds were endowed with a satisfactory activity (Table 4). Overall the activity of the compounds was remarkable, albeit not comparable to celecoxib. Noteworthy, compound $\mathbf{3 c}$ (in vitro more active than celecoxib) was less effective and had a shorter duration of action in the in vivo test. The shorter duration of the pharmacological effect suggested a possible metabolic deactivation for compound $\mathbf{3 c}$ and/ or other pharmacokinetic issues.

\subsection{NO-coxibs based on diarylpyrrole scaffold: esters, the solubility} issue

Since the pharmacokinetic issues affecting the in vivo effects seen with compounds $\mathbf{3 c}$-d, in addition to metabolism, can also be due to absorption, the compounds' solubility was investigated as well. Simulated gastric fluid (SGF-without pepsin) and phosphate buffered saline (PBS) were chosen to evaluate the solubility in acid ( $\mathrm{pH} 1.5$ for SGF) and neutral conditions (7.4 pH for PBS). The solubility of $3 \mathrm{c}$ was $<1 \mu \mathrm{M}$ and $1.6 \mu \mathrm{M}$ respectively in SGF and PBS; similarly, the solubility for compound $4 \mathrm{c}$ was $1<\mu \mathrm{M}$ and $1.1 \mu \mathrm{M}$ respectively in SGF and PBS [69]. These molecules were then characterised by low solubility and this feature could heavily affect their absorption. In order to increase solubility an ionisable moiety was added to the scaffold, thus an amino group was introduced at the $\alpha$-position of the acetic side chain, since previous SAR studies highlighted this as a favourable position for such a change [64]. Compounds 5a-d along with their corresponding derivatives 6ad were prepared for exploring the approach (Table 5) [69]. The NOrelease properties of the compounds were appropriate (5a: $\mathrm{E}_{\max }=84.0 \pm 2.0 ; \mathrm{plC}_{50}=5.66 \pm 0.03 ; 5 \mathrm{c}: \mathrm{E}_{\max }=93.0 \pm 1.0$; $\mathrm{pIC}_{50}=5.81 \pm 0.03$ ) [69]. As expected, the ionisable moiety determined a remarkable increase of solubility. Solubility of $\mathbf{5 a}$ was $>200 \mu \mathrm{M}$ and $70.8 \mu \mathrm{M}$, respectively in SGF and PBS, and solubility for compound 5b was $>200 \mu \mathrm{M}$ and $80.0 \mu \mathrm{M}$, respectively in SGF and PBS. Despite the cell-based assay for COX activity showed a reduction in the potency for compounds 5a-d and 6a-d in comparison with $\mathbf{3 c - d}$ and $\mathbf{3 e - f}$ (Table 1), the writhing test highlighted for compounds $\mathbf{5 a}$ and $\mathbf{5 c}$ (Table 6) [69] activities comparable to those of compounds $\mathbf{3 c}$-d. This finding strongly pointed out the solubility among the causes responsible for the drop of the in vivo activity seen with compounds $\mathbf{3 c - 3 d}$. Compound $\mathbf{5 a}$ was selected

Table 4

Effect of 3c-d, 4c-d, Celecoxib, and vehicle (CMC) on hyperalgesia and edema induced by carrageenan in the rat paw pressure test ${ }^{a}$.

\begin{tabular}{|c|c|c|c|c|c|c|c|}
\hline \multicolumn{8}{|c|}{ paw pressure (g) } \\
\hline $\begin{array}{l}\text { pretreatment, } \\
\text { ipl }\end{array}$ & $\begin{array}{l}\text { treatment, } \\
\text { po }\end{array}$ & dose $\mathrm{mg} / \mathrm{kg}$ & before treatment & & after treatment & & volume (mL) \\
\hline & & & & $30 \mathrm{~min}$ & $60 \mathrm{~min}$ & $120 \mathrm{~min}$ & $60 \mathrm{~min}$ \\
\hline saline & CMC & & $62.6 \pm 2.1$ & $62.5 \pm 1.8$ & $63.4 \pm 2.2$ & $62.7 \pm 2.5$ & $1.33 \pm 0.07$ \\
\hline carrageenan & CMC & & $61.9 \pm 2.0$ & $33.7 \pm 2.6$ & $35.1 \pm 2.3$ & $34.8 \pm 2.3$ & $2.44 \pm 0.08$ \\
\hline carrageenan & $3 c$ & 20 & $32.6 \pm 2.7$ & $40.1 \pm 3.4$ & $35.3 \pm 2.8$ & ND & $2.52 \pm 0.06$ \\
\hline carrageenan & $3 c$ & 40 & $29.8 \pm 3.1$ & $54.1 \pm 3.7 *$ & $38.7 \pm 3.1$ & ND & $2.17 \pm 0.08^{*}$ \\
\hline carrageenan & $3 c$ & 100 & $31.9 \pm 3.0$ & $57.2 \pm 3.5 *$ & $36.5 \pm 3.8$ & ND & $1.88 \pm 0.08 *$ \\
\hline carrageenan & 3d & 20 & $62.5 \pm 3.1$ & $43.2 \pm 3.2$ & $45.1 \pm 3.7 \wedge$ & $40.7 \pm 2.6$ & $2.05 \pm 0.08 \wedge$ \\
\hline carrageenan & 3d & 40 & $63.2 \pm 3.3$ & $45.5 \pm 3.7 *$ & $44.9 \pm 4.2 \wedge$ & $36.8 \pm 3.8$ & $1.96 \pm 0.09 *$ \\
\hline carrageenan & $4 c$ & 30 & $31.8 \pm 2.5$ & $55.7 \pm 3.1^{*}$ & $52.3 \pm 2.8^{*}$ & $39.3 \pm 3.5$ & $2.51 \pm 0.05$ \\
\hline carrageenan & $4 d$ & 20 & $62.6 \pm 3.1$ & $41.2 \pm 3.0$ & $45.8 \pm 3.6 \wedge$ & $36.4 \pm 3.1$ & ND \\
\hline carrageenan & 4d & 40 & $61.3 \pm 3.0$ & $43.1 \pm 3.6$ & $48.8 \pm 3.6^{*}$ & $44.4 \pm 3.3 \wedge$ & $\mathrm{ND}$ \\
\hline carrageenan & Celecoxib & 10 & $61.5 \pm 3.4$ & $54.3 \pm 3.9 *$ & $57.1 \pm 4.0^{*}$ & $54.9 \pm 3.6 *$ & $1.36 \pm 0.07 *$ \\
\hline
\end{tabular}

${ }^{a}$ Doses are expressed in $\mathrm{mg} / \mathrm{kg}$. The equivalent doses in $\mu \mathrm{mol} / \mathrm{kg}$ are indicated in parentheses. $*, P<0.01$ versus vehicle-treated mice. ND, not determined. $\wedge, P<0.05$.

Table 5

COX-1 and COX-2 inhibitory activity of 5a-d, 6a-d, and Celecoxib.

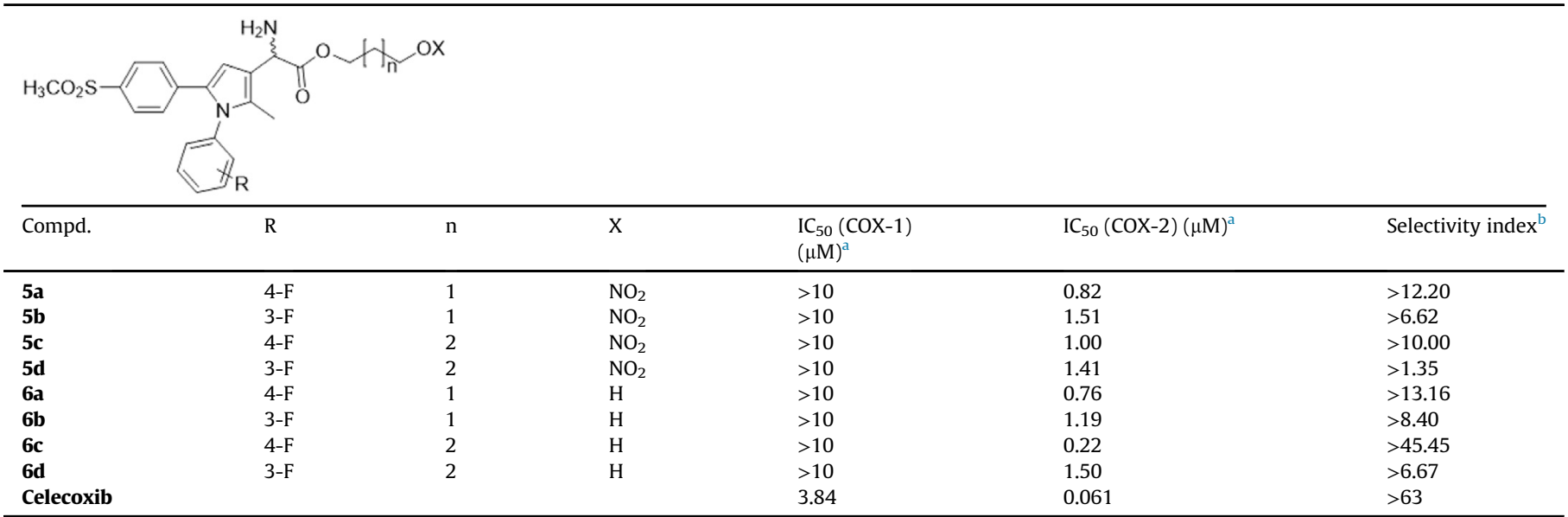

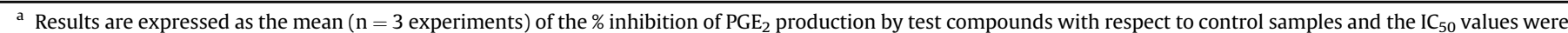
calculated by GraphPad Instat program; data fit was obtained using the sigmoidal dose-response equation (variable slope) (GraphPad software).

b In vitro COX-2 Selectivity Index $\left[\mathrm{IC}_{50}(\mathrm{COX}-1) / \mathrm{IC}_{50}(\mathrm{COX}-2)\right]$. 
Table 6

Effect of $\mathbf{5 a}$ and $\mathbf{5 c}$ and vehicle (CMC) in the mouse abdominal constriction test (Acetic acid 0.6\%).

\begin{tabular}{lllll}
\hline Compound $^{\mathrm{a}}$ & \multicolumn{2}{l}{ Dose per p.o. } & N. writhes & \% of writhes reduction \\
\cline { 2 - 3 } & $\mathrm{mg} / \mathrm{kg}$ & $\mu \mathrm{mol} / \mathrm{kg}$ & & \\
\hline CMC & & & $33.4 \pm 2.5$ & - \\
$\mathbf{5 a}$ & 3 & 5.5 & $26.9 \pm 2.6$ & 19.0 \\
& 10 & 18.4 & $21.3 \pm 2.5^{*}$ & 36.2 \\
& 20 & 36.8 & $18.1 \pm 3.0^{*}$ & 46.1 \\
& 40 & 73.6 & $13.5 \pm 2.8^{*}$ & 59.6 \\
$\mathbf{5 c}$ & 20 & 35.9 & $24.5 \pm 3.2$ & 26.9 \\
& 40 & 71.8 & $19.8 \pm 2.4^{*}$ & 40.7 \\
\hline
\end{tabular}

${ }^{b}$ Doses are expressed in $\mathrm{mg} / \mathrm{kg}$. The equivalent doses in $\mu \mathrm{mol} / \mathrm{kg}$ are indicated in parentheses. ${ }^{*}, P<0.01$ versus vehicle-treated mice. $\wedge, P<0.05$.

a All compounds were administered per os $30 \mathrm{~min}$ before test.

for the carrageenan test: its in vivo activity (Table 7) was equivalent to the one of compound $\mathbf{3 c}$, more potent in vitro. However, the duration of action of $\mathbf{5 a}$ is still shorter than celecoxib, pointing out the presence of a metabolic issue as well.

\subsection{NO-coxibs based on diarylpyrrole scaffold: amides}

Though the metabolism of the nitroxy derivatives may be complex, the pathway leading to the hydroxylated derivatives is widely considered as the most usual metabolic destiny of organic nitrates [77]. However, for naproxcinod and related CINODs, the esterase mediated hydrolysis into the NSAID scaffold and NOBA, followed by further metabolic conversion of the nitroester was proved to be the major metabolic pathway [78]. Accordingly, the hydrolysis of alkyl esters into the corresponding acid and nitroxy alcohol could be expected also for compounds 3a-h. Since the enzymatic liability of the esters, was considered to be a remarkable factor in the gap between in vitro and in vivo pharmacological profiles of the compounds discussed at paragraph 2.1, four different groups of compounds (Table 8) were generated through replacement of the ester moiety with the amide group, in order to address the structural issues impacting both stability and solubility [68,71].

Firstly, a class of "simple" amides obtained through the replacement of the ester moiety with the amide group was explored. The diarylpyrrole-3-acetic scaffold was retained and the substitution pattern as well as the side-chain length were based on the previously discussed SAR. Compounds 7a-d and the expected metabolites 8a-d (Table 8) were synthesised and tested. Amide derivatives (7a-d) displayed a COX-2 inhibition ranging from 0.25 to $0.31 \mu \mathrm{M}$, and the corresponding hydroxylated analogues (8a-d) highlighted a COX-2 inhibition ranging from 0.045 to $0.30 \mu \mathrm{M}$. The NO-releasing properties for compounds $\mathbf{7 a - c}$ are reported in Table 9. While compound 7a showed low vasorelaxing effect, compounds $\mathbf{7 b}$ and $\mathbf{7 c}$ were endowed with good efficacy, with $\mathrm{pIC}_{50}$ spanning from 5.78 (7b) to 5.31 (7c). ODQ antagonized the vasorelaxing activity of these compounds.

In the second group of compounds (Table 8), in addition to the replacement of the ester moiety with the amide group, a carboxylate group was added to the $\alpha$-position of the acetic moiety in order to increase solubility. The corresponding serine/homoserine derivatives 9a-d and 10a-d were synthesised and tested [71]. The homoserine derivatives were in general more potent in COX-2 inhibition than the corresponding serine derivatives, with $\mathrm{IC}_{50}$ ranging from 0.14 to $1.6 \mu \mathrm{M}$, the corresponding hydroxylated derivatives (10a-d) were effective in the range $\mathrm{IC}_{50} 0.068-0.16 \mu \mathrm{M}$. However, 9a-d produced unsatisfactory vasorelaxing effects (Table 9), probably due to the presences of the unfavourable carboxylate moiety. In the third group of compounds (Table 8), in addition to the introduction of the amide group, an amino group was added to the $\alpha$-position of the acetic moiety to increase solubility. The derivatives 11a-b and corresponding possible metabolites 12a-b were synthesised [71]. A good activity for COX-2 inhibition was found for both the compounds with the higher potency for 11a $\left(\mathrm{IC}_{50}=0.054 \mu \mathrm{M}\right)$. Interestingly, the hydroxylated derivative 12a lacked any relevant COX inhibitory activity, while 12b was effective $\left(\mathrm{IC}_{50}=0.047 \mu \mathrm{M}\right)$. The introduction of the amide group within the glycine skeleton, did not compromise the NOmediated vasorelaxing effects. Compounds 11a and 11b exhibited high levels of vasorelaxing efficacy and good potencies, with $\mathrm{pIC}_{50}=6.38$ for both compounds (Table 9). ODQ significantly antagonized the vasorelaxing activity.

Compounds 13a-b and 14a-b (Table 8) form the fourth group: in addition to the replacement of the ester moiety with the amide group, the compounds were manipulated in the 5-phenyl ring where the 4-sulfonyl moiety was replaced with the 4-sulfamoyl group to increase solubility [68]. However, COX-2 inhibitory potency for these compounds was rather low $\left(\mathrm{IC}_{50}>10 \mu \mathrm{M}\right)$ although the NO releasing properties were appropriate.

The selectivity for COX-2 inhibition was also assessed using the HWB assays for the most effective compounds $\mathbf{7 c}$ and 11a, along with the derivatives $\mathbf{8 c}$ and 12a [71]. Compound 7c displayed a concentration-dependent inhibition of COX-1 and COX-2 with $\mathrm{IC}_{50}$ of 0.6 and $1.7 \mu \mathrm{M}$, respectively. Its derivative $\mathbf{8 c}$, inhibited COX-2 and COX-1 activities with similar $\mathrm{IC}_{50}: 1.4$ and $1.9 \mu \mathrm{M}$, respectively. Thereby, in the HWB assay $\mathbf{7 c}$ and its metabolite $\mathbf{8 c}$ proved to be non-selective COX inhibitors ( $\mathrm{SI}=0.3$ ). On the other hand, compound 11a inhibited COX-2 and COX-1 activities in a concentration-dependent fashion with $\mathrm{IC}_{50}: 21$ and $140 \mu \mathrm{M}$, respectively. Compound 11a was then significantly more potent towards COX-2 than COX-1 ( $\mathrm{IC}_{50}$, ratio: 6.7). The corresponding derivative 12a inhibited COX-2 activity with an $\mathrm{IC}_{50}$ value of 13.7 and was less potent in COX-1 inhibition $\left(\mathrm{IC}_{50}=300 \mu \mathrm{M}\right)(\mathrm{SI}=22)$ [71].

The kinetics of NO-release for compounds 7c and 11a were compared with naproxcinod [71]. The time-dependent increase of

Table 7

Activity of compound 5a and Celecoxib in the carrageenan-induced inflammation ${ }^{a}$.

\begin{tabular}{|c|c|c|c|c|c|c|c|c|}
\hline \multirow[t]{3}{*}{ Pre-treatment ipl } & \multirow[t]{3}{*}{ Treatment p.o. } & \multirow[t]{3}{*}{ Dose } & \multirow[t]{3}{*}{ Before treatment } & \multicolumn{4}{|c|}{ Paw-pressure } & \multirow[t]{3}{*}{ Edema volume $(\mathrm{mL})$} \\
\hline & & & & \multicolumn{4}{|c|}{ After treatment } & \\
\hline & & & & $15 \mathrm{~min}$ & $30 \mathrm{~min}$ & $45 \mathrm{~min}$ & $60 \mathrm{~min}$ & \\
\hline Saline & CMC & - & $61.2 \pm 2.5$ & $65.6 \pm 3.4$ & $58.9 \pm 3.8$ & $61.4 \pm 4.1$ & $63.6 \pm 4.0$ & $1.44 \pm 0.05$ \\
\hline Carrageenan & CMC & - & $36.1 \pm 3.3$ & $32.8 \pm 2.9$ & $30.6 \pm 3.2$ & $31.8 \pm 2.2$ & $34.8 \pm 3.1$ & $2.71 \pm 0.08$ \\
\hline Carrageenan & $5 a$ & 20 & $33.8 \pm 2.8$ & $40.2 \pm 3.6$ & $43.7 \pm 3.7$ & $38.3 \pm 3.1$ & $37.1 \pm 3.0$ & $2.58 \pm 0.05$ \\
\hline Carrageenan & $5 a$ & 40 & $32.9 \pm 3.0$ & $45.4 \pm 3.2$ & $50.2 \pm 4.4$ & $45.6 \pm 4.3$ & $37.5 \pm 2.8$ & $2.11 \pm 0.09$ \\
\hline Carrageenan & Celecoxib & 10 & $31.7 \pm 2.7$ & $45.7 \pm 4.2$ & $52.9 \pm 3.1$ & $48.3 \pm 3.4$ & $42.5 \pm 2.9$ & $2.53 \pm 0.05$ \\
\hline
\end{tabular}

${ }^{a}$ Doses are expressed in $\mathrm{mg} / \mathrm{kg}$. The equivalent doses in $\mu \mathrm{mol} / \mathrm{kg}$ are indicated in parentheses. ${ }^{*}, P<0.01$ versus vehicle-treated mice. ND, not determined. $\wedge, P<0.05$. 
Table 8

COX-1 and COX-2 inhibitory activity of 7a-d, 8a-d, 9a-d, 10a-d, 11a-b, 12a-b, 13a-b, 14a-b and Celecoxib.

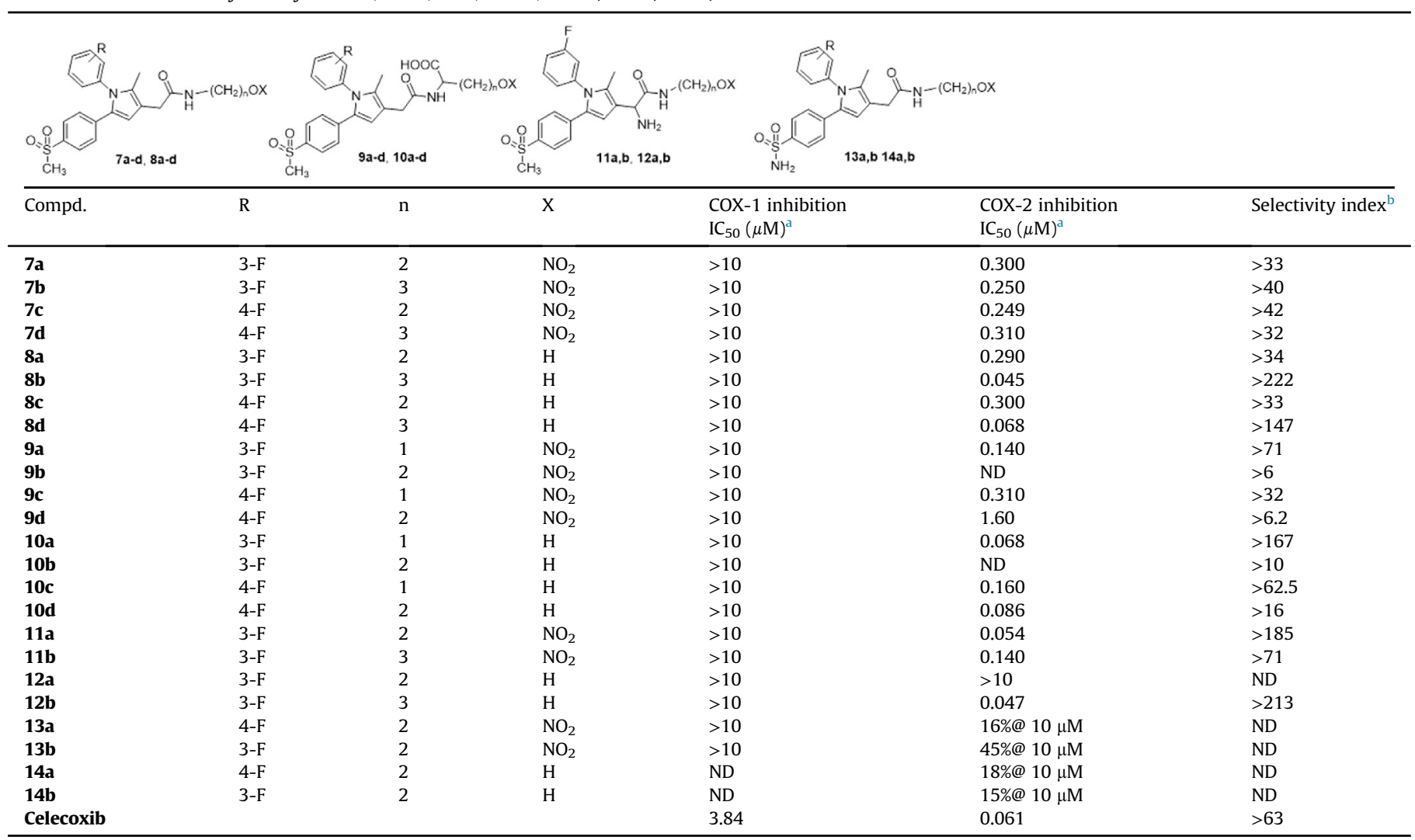

${ }^{a}$ Results are expressed as the mean ( $\mathrm{n}=3$ experiments) of the percentage inhibition of PGE2 production by test compounds with respect to control samples and the IC 50 values were calculated by GraphPad Instat program; data fit was obtained using the sigmoidal dose-response equation (variable slope) (GraphPad software).

b In vitro COX-2 selectivity index $\left[\mathrm{IC}_{50}(\mathrm{COX}-1) / \mathrm{IC}_{50}(\mathrm{COX}-2)\right]$.

the concentrations of inorganic nitrites and nitrates (stable NO metabolites) was measured after incubation $(2 \mathrm{~h})$ of the compounds in rat liver homogenates. The nitrite concentration for $\mathbf{7 c}$ was $27.0 \pm 12.1 \mu \mathrm{M}$, while corresponding nitrate concentration was $38.3 \pm 4.3 \mu \mathrm{M}$. Compound 11a, in the same conditions, showed $42.9 \pm 6.6 \mu \mathrm{M}$ and $56.1 \pm 16.0 \mu \mathrm{M}$ for nitrites and nitrates respectively. These data indicate that both compounds are endowed with a slow NO-releasing rate, which is a fundamental feature for the development of well-balanced hybrids. Conversely, Naproxcinod exhibited after $2 \mathrm{~h}$, the highest concentration $(367.7 \pm 11.4 \mu \mathrm{M})$, of

Table 9

Vasorelaxing properties for compounds $7 \mathbf{a}-\mathbf{c}, \mathbf{9 a}-\mathbf{d}, \mathbf{1 1} \mathbf{a}-\mathbf{b}$ and 13a-b.

\begin{tabular}{lll}
\hline Compd. & $\mathrm{E}_{\max }{ }^{\mathrm{a}}$ & $\mathrm{pIC}_{50}{ }^{\mathrm{b}}$ \\
\hline 7a & $49.0 \pm 2.0$ & $\mathrm{NC}$ \\
7b & $69.0 \pm 8.0$ & $5.78 \pm 0.07$ \\
7c & $68.0 \pm 0.5$ & $5.31 \pm 0.05$ \\
$\mathbf{9 a}$ & $18.0 \pm 9.0$ & $\mathrm{NC}$ \\
$\mathbf{9 b}$ & $25.0 \pm 2.0$ & $\mathrm{NC}$ \\
$\mathbf{9 c}$ & $25.0 \pm 1.9$ & $\mathrm{NC}$ \\
$\mathbf{9 d}$ & $42.0 \pm 9.0$ & $\mathrm{NC}$ \\
$\mathbf{1 1 a}$ & $74.1 \pm 1.0$ & $5.38 \pm 0.20$ \\
$\mathbf{1 1 b}$ & $86.0 \pm 2.0$ & $5.38 \pm 0.03$ \\
$\mathbf{1 3 a}$ & $74.9 \pm 2.5$ & $5.82 \pm 0.04$ \\
13b & $67.5 \pm 2.3$ & $5.49 \pm 0.00$ \\
Naproxcinod & $68.0 \pm 3.0$ & $6.33 \pm 0.06$ \\
\hline
\end{tabular}

${ }^{a}$ Emax represents the vasorelaxing efficacy, expressed as a \% of the vasoconstriction induced by the pre-administration of $\mathrm{KCl}$.

b Parameter of potency is expressed as $\mathrm{pIC}_{50}$, representing - log of the molar concentration capable of inducing a vasorelaxing effect $=50 \%$ of $\mathrm{E}_{\max }$. nitrate and nitrites (NOx). Interestingly, the concentration of NOx was largely due to the released nitrates $(340.1 \pm 5.0 \mu \mathrm{M})$ while a lower concentration of nitrites was detected $(27.6 \pm 6.2 \mu \mathrm{M})$. Such a lower ratio nitrites/NOx would suggest that only a small part of the nitro-oxy group of naproxcinod is converted to NO and that a direct hydrolysis to inorganic nitrate is prevalent. Indeed, NOBA is a relatively fast NO-releasing compound, and the CV effects are detected for a maximum of $3 \mathrm{~h}$ after the naproxcinod administration. Conversely, the analgesic and anti-inflammatory effects of naproxcinod are more extended because of the long half-life (i.e., $17 \mathrm{~h}$ ) of naproxen, thus not assuring the GI/CV protection for the whole duration of the COX inhibition.

Solubility of compounds was assessed in SGF and PBS (Table 10) [71]. The replacement of the ester functionality with the amide moiety provided in general more soluble molecules. The best solubility profile was displayed by the glycine amide 11a $(>200 \mu \mathrm{M}$ in both SGF and PBS). Comparative stability studies of the esters 3c and $\mathbf{5 c}$ with amides $\mathbf{7 c}, \mathbf{9 a}, \mathbf{1 1} \mathbf{a}$, revealed liability of the esters to

Table 10

Solubility in SGF and PBS for compounds 3c, 5c, 7a, 7c, 9c, 11a.

\begin{tabular}{lll}
\hline Compd. & SGF $(\mathrm{pH} 1.5)(\mu \mathrm{M})$ & PBS $(\mathrm{pH} 7.4)(\mu \mathrm{M})$ \\
\hline $\mathbf{3 c}$ & $<1$ & 1.6 \\
$\mathbf{5 c}$ & $>200$ & 80 \\
$\mathbf{7 a}$ & 150 & $>200$ \\
$\mathbf{7 c}$ & 147 & $>200$ \\
$\mathbf{9 c}$ & 112 & 90.5 \\
$\mathbf{1 1 a}$ & $>200$ & 200 \\
\hline
\end{tabular}


Table 11

Stability in SGF, PBS and rat plasma for compounds 3c, 5c, 7a, 9a and 11a.

\begin{tabular}{lllll}
\hline \multirow{2}{*}{ Compd. } & Time $(\mathrm{min})$ & \multicolumn{3}{l}{ Parent molecule remained $(\%)$} \\
\cline { 3 - 5 } & & PBS $(\mathrm{pH} 7.4)$ & SGF $(\mathrm{pH} 1.5)$ & Rat plasma \\
\hline \multirow{2}{*}{ 3c } & 30 & 74.1 & 80.2 & 0.00 \\
& 60 & 53.6 & 65.7 & 0.00 \\
& 120 & 0.15 & 42.8 & 0.00 \\
$\mathbf{5 c}$ & 30 & 75.0 & 100 & 0.00 \\
& 60 & 75.0 & 100 & 0.00 \\
& 120 & 75.0 & 100 & 0.00 \\
7c & 30 & 100 & 100 & 100 \\
& 60 & 100 & 100 & 100 \\
& 120 & 100 & 100 & 100 \\
9a & 30 & 75 & 100 & 71 \\
& 60 & 50 & 93.8 & 57 \\
& 120 & 37.5 & 87.5 & 28.6 \\
11a & 30 & 100 & 100 & 94 \\
& 60 & 100 & 100 & 93 \\
& 120 & 100 & 100 & 77 \\
\hline
\end{tabular}

hydrolysis in comparison with amides (Table 11). Compound 7c was completely resistant to hydrolysis, whereas compound 11a was relatively more liable in rat plasma (even though after $120 \mathrm{~min}$ of incubation $77 \%$ of the compound was still detected).

All the nitrooxyamides were tested in the writhing test, and highlighted a good and dose-dependent activity (Table 12) [71]. In particular, compound 7c, and glycine derivative 11a were endowed with the higher potency, displaying respectively $77 \%$ and $79 \%$ of reduction at $20 \mathrm{mg} / \mathrm{kg}$. Moreover, compound 11a displayed writhes reduction of $56 \%$ at the dose of $10 \mathrm{mg} / \mathrm{kg}$. The most active nitro-oxy compounds 7c and 11a were also evaluated for their activity in the carrageenan induced edema and hyperalgesia (Table 13) [71]. The carrageenan induced inflammation test showed that $\mathbf{7 c}$ was associated with a good but not outstanding activity. Conversely, compound 11a was proved to be highly active, with a reduction of hyperalgesia at $10 \mathrm{mg} / \mathrm{kg}$ of $80 \%$ after $30 \mathrm{~min}$. The activity was maintained for $60 \mathrm{~min}(70 \%)$ and even after $90 \mathrm{~min}$ a satisfactory activity (50\%) was still found.

The pharmacokinetics of the best performing compounds $7 \mathrm{c}$ and 11a were assessed in rats after po and iv administration at $10 \mathrm{mg} / \mathrm{kg}$ [71]. After iv administration, 7c was detected in plasma up to $6 \mathrm{~h}$. Both 7c and 11a appear to be characterized by moderate to high rate of clearance and high volume of distribution. Compound 7c showed absolute bioavailability (24\%) higher than 11a (9\%). The presence of the metabolites 8c and 12a was also

Table 12

Effect of $\mathbf{1 a}-\mathbf{d}, \mathbf{4 c}, \mathbf{2 a}-\mathbf{d}, \mathbf{5 c}$, and 3a,b and vehicle (CMC) in the mouse abdominal constriction test (Acetic acid $0.6 \%$ ).

\begin{tabular}{|c|c|c|c|c|}
\hline Compd. & n. mice & Dose po $\mathrm{mg} / \mathrm{kg}$ & n. Writhes after $30 \mathrm{~min}$ & Writhes reduction (\%) \\
\hline CMC & 23 & - & $32.6 \pm 2.1$ & - \\
\hline \multirow[t]{3}{*}{$7 a$} & 10 & 10 & $26.8 \pm 2.1 * *$ & 18 \\
\hline & 10 & 20 & $20.6 \pm 3.0 *$ & 37 \\
\hline & 10 & 40 & $14.7 \pm 2.1^{*}$ & 55 \\
\hline \multirow[t]{3}{*}{ 7b } & 9 & 10 & $33.2 \pm 3.5$ & 0 \\
\hline & 9 & 20 & $29.8 \pm 3.6$ & 8.6 \\
\hline & 10 & 40 & $22.9 \pm 2.2 *$ & 30 \\
\hline \multirow[t]{3}{*}{ 7c } & 9 & 10 & $12.2 \pm 2.3^{*}$ & 63 \\
\hline & 9 & 20 & $7.4 \pm 1.3 *$ & 77 \\
\hline & 10 & 40 & $8.1 \pm 1.2 *$ & 75 \\
\hline \multirow[t]{3}{*}{$7 d$} & 8 & 3 & $27.2 \pm 2.7$ & 17 \\
\hline & 8 & 10 & $20.4 \pm 2.2 *$ & 37 \\
\hline & 8 & 20 & $21.6 \pm 2.8^{*}$ & 34 \\
\hline \multirow[t]{2}{*}{$8 c$} & 10 & 10 & $20.7 \pm 3.5 *$ & 37 \\
\hline & 10 & 20 & $12.6 \pm 2.7 *$ & 61 \\
\hline \multirow[t]{3}{*}{ 9a } & 10 & 10 & $28.3 \pm 2.5$ & 12 \\
\hline & 10 & 20 & $17.1 \pm 3.1^{*}$ & 47 \\
\hline & 10 & 40 & $16.4 \pm 2.9 *$ & 50 \\
\hline \multirow[t]{2}{*}{ 9b } & 8 & 20 & $29.2 \pm 2.4$ & 10 \\
\hline & 10 & 40 & $25.2 \pm 3.3 * *$ & 23 \\
\hline \multirow[t]{3}{*}{$9 c$} & 8 & 10 & $33.1 \pm 3.5$ & 0 \\
\hline & 9 & 20 & $23.2 \pm 2.3^{*}$ & 29 \\
\hline & 10 & 40 & $16.3 \pm 3.2 *$ & 50 \\
\hline \multirow[t]{3}{*}{ 9d } & 10 & 3 & $33.7 \pm 3.0$ & 0 \\
\hline & 10 & 10 & $22.8 \pm 2.7 *$ & 30 \\
\hline & 11 & 20 & $14.9 \pm 2.8 *$ & 54 \\
\hline \multirow[t]{3}{*}{$10 c$} & 14 & 10 & $23.7 \pm 3.0$ & 27 \\
\hline & 15 & 20 & $13.4 \pm 2.8 *$ & 59 \\
\hline & 15 & 40 & $12.9 \pm 2.1^{*}$ & 60 \\
\hline \multirow[t]{3}{*}{ 11a } & 13 & 3 & $25.1 \pm 2.3 * *$ & 23 \\
\hline & 10 & 10 & $14.2 \pm 2.9 *$ & 56 \\
\hline & 13 & 20 & $6.7 \pm 2.0 *$ & 79 \\
\hline \multirow[t]{3}{*}{ 11b } & 9 & 10 & $30.5 \pm 2.6$ & 6 \\
\hline & 10 & 20 & $21.4 \pm 3.7 *$ & 34 \\
\hline & 10 & 40 & $18.8 \pm 3.1^{*}$ & 42 \\
\hline \multirow[t]{4}{*}{ 13a } & 10 & 5 & $26.7 \pm 3.3 *$ & 20.5 \\
\hline & 10 & 10 & $18.5 \pm 4.2 *$ & 44.9 \\
\hline & 8 & 20 & $15.8 \pm 3.7 *$ & 53.0 \\
\hline & 9 & 40 & $16.7 \pm 2.5^{*}$ & 50.3 \\
\hline \multirow[t]{3}{*}{$13 b$} & 5 & 1 & $21.8 \pm 3.5^{*}$ & 35.1 \\
\hline & 5 & 3 & $19.4 \pm 2.9 *$ & 42.3 \\
\hline & 6 & 10 & $16.7 \pm 3.5^{*}$ & 50.3 \\
\hline Celecoxib & 13 & 10 & $13.5 \pm 3.0 *$ & 59 \\
\hline
\end{tabular}

$* \mathrm{P}<0.01$.

$* * \mathrm{P}<0.05$ in comparison with $\mathrm{CMC}$ treated animals. 
Table 13

Hyperalgesia and edema reduction in the carrageenan induced inflammation for compounds 7c and 11a in comparison with celecoxib.

\begin{tabular}{|c|c|c|c|c|c|c|c|c|}
\hline \multirow[t]{2}{*}{ pretreatment, ipl } & \multicolumn{8}{|c|}{ paw pressure (g) } \\
\hline & $\begin{array}{l}\text { treatment } \\
\text { po }\end{array}$ & dose $\mathrm{mg} / \mathrm{kg}$ & before treatment & after treatme & & & & volume $(\mathrm{mL})^{b}$ \\
\hline & & & & $30 \mathrm{~min}$ & $60 \mathrm{~min}$ & $90 \mathrm{~min}$ & $120 \mathrm{~min}$ & $60 \mathrm{~min}$ \\
\hline Saline & CMC & & $61.6 \pm 3.4$ & $58.9 \pm 3.8$ & $61.4 \pm 4.1$ & $61.4 \pm 4.1$ & $61.4 \pm 4.1$ & $1.44 \pm 0.05$ \\
\hline Carrageenan & CMC & & $36.1 \pm 3.3$ & $32.8 \pm 2.9$ & $30.6 \pm 3.2$ & $31.8 \pm 2.2$ & $31.8 \pm 2.2$ & $2.71 \pm 0.08$ \\
\hline Carrageenan & $7 c$ & 20 & $33.8 \pm 2.9$ & $40.7 \pm 3.5^{* *}$ & $42.8 \pm 3.4^{* *}$ & $37.8 \pm 2.6$ & $37.8 \pm 2.6$ & $2.63 \pm 0.05$ \\
\hline Carrageenan & & 40 & $32.9 \pm 3.3$ & $44.2 \pm 4.0^{*}$ & $48.3 \pm 4.6$ & $41.5 \pm 3.7^{*}$ & $31.5 \pm 2.6$ & $2.50 \pm 0.09$ \\
\hline Carrageenan & 11a & 20 & $33.8 \pm 2.9$ & $55.2 \pm 3.3^{*}$ & $52.1 \pm 4.2^{*}$ & $47.3 \pm 3.7^{*}$ & $39.5 \pm 3.0$ & $1.79 \pm 0.09 *$ \\
\hline Carrageenan & Celecoxib & 10 & $31.7 \pm 2.7$ & $45.7 \pm 4.2^{*}$ & $52.9 \pm 3.1 *$ & $48.3 \pm 3.4^{*}$ & $42.5 \pm 2.9$ & $2.53 \pm 0.05^{*}$ \\
\hline
\end{tabular}

$* \mathrm{P}<0.01$.

$* * \mathrm{P}<0.05$ in comparison with CMC treated animals.

measured. Compound 8c was detected in rat plasma up to $6 \mathrm{~h}$ after both iv and po administrations, while 12a was detected in rat plasma at least up to $6 \mathrm{~h}$ after intravenous administrations and only up to $2 \mathrm{~h}$ after oral administration. For 7c, after intravenous administration at least $39 \%$ of the parent compound was converted into the metabolite 8c while after oral administration $99 \%$ of the parent compound was converted into the metabolite, suggesting that after oral administration $\mathbf{7 c}$ is readily metabolized to $\mathbf{8 c}$. For 11a, after intravenous administration only $10 \%$ of the parent compound was converted into the metabolite 12a during the $6 \mathrm{~h}$ of the experiment.

\subsection{NO-coxibs based on diarylpyrrole scaffold: ethers}

In order to further increase the stability of the linker between the scaffold and the NO releasing moiety, the corresponding ethers 15a-f (Table 14) [64,67] were prepared. The conversion of the nitrooxyalkyl ester into the nitrooxyalkyl ether moiety led to potent COX-2 inhibitors. Results for compounds 15a-f, and corresponding metabolites 16a-f, in the COX inhibition (J774 cells assay) are reported in Table 14. Some of them were endowed with good NOdonating properties (Table 15) [67] along with quite good and selective COX-2 inhibitory activity ranging from low nanomolar to
Table 15

Efficacy and potency in determining NO-dependent vasorelaxing responses of 15a-f and GTN. ${ }^{a}$.

\begin{tabular}{lll}
\hline Compd. & $\mathrm{E}_{\max }{ }^{\mathrm{b}}$ & $\mathrm{pIC}_{50}{ }^{\mathrm{c}}$ \\
\hline 15a & $65 \pm 3$ & $5.22 \pm 0.03$ \\
15b & $48 \pm 5$ & $\leq 5$ \\
15c & $60 \pm 4$ & $5.32 \pm 0.05$ \\
15d & $\mathrm{ND}$ & - \\
15e & $58 \pm 5$ & $5.47 \pm 0.07$ \\
15f & $41 \pm 2$ & $\leq 5$ \\
GNT & $93 \pm 2$ & $6.90 \pm 0.07$ \\
\hline
\end{tabular}

${ }^{a}$ GTN: glyceryl trinitrate.

b Emax represents the vasorelaxing efficacy, expressed as a \% of the vasoconstriction induced by the pre-administration of $\mathrm{KCl}$.

c Parameter of potency is expressed as $\mathrm{pIC}_{50}$, representing - $\log$ of the molar concentration capable of inducing a vasorelaxing effect $=50 \%$ of $\mathrm{E}_{\max }$.

micromolar values. Nitrooxyalkyl ethers 15a-f highlighted a better COX-2 inhibitory activity with respect to derivatives 16a-f, most of the compounds were as active as corresponding nitrooxyalkyl esters. Compounds 15a $(n=2, H), \mathbf{1 5 b}(n=3, H), \mathbf{1 5} \mathbf{c}(n=2,3-F), \mathbf{1 5 d}$ $(\mathrm{n}=3,3-\mathrm{F})$ emerged as low nanomolar COX-2 inhibitors. Compounds 15a, 15c and 15e showed better NO-vasorelaxing responses in comparison with the other compounds of the group (Table 15),

Table 14

COX-1 and COX-2 inhibitory activity Compounds $\mathbf{1 5}$ a-f, 16a-f, and Celecoxib.

\begin{tabular}{|c|c|c|c|c|c|c|}
\hline Compd. & $\mathrm{R}$ & $\mathrm{n}$ & $\mathrm{X}$ & $\begin{array}{l}\text { COX-1 inhibition } \\
\mathrm{IC}_{50}(\mu \mathrm{M})^{\mathrm{a}}\end{array}$ & $\begin{array}{l}\text { COX-2 inhibition } \\
\mathrm{IC}_{50}(\mu \mathrm{M})^{\mathrm{a}}\end{array}$ & Selectivity index ${ }^{\mathrm{b}}$ \\
\hline $15 a$ & $\mathrm{H}$ & 2 & $\mathrm{NO}_{2}$ & $>10$ & 0.017 & $>588.2$ \\
\hline $15 b$ & $\mathrm{H}$ & 3 & $\mathrm{NO}_{2}$ & $>10$ & 0.015 & $>666.7$ \\
\hline $15 c$ & $3-F$ & 2 & $\mathrm{NO}_{2}$ & $>10$ & 0.027 & $>357.1$ \\
\hline 15d & $3-\mathrm{F}$ & 3 & $\mathrm{NO}_{2}$ & 2.9 & 0.023 & 126.1 \\
\hline $15 e$ & $4-\mathrm{F}$ & 2 & $\mathrm{NO}_{2}$ & $>10$ & 0.014 & $>714.3$ \\
\hline $15 f$ & $4-\mathrm{F}$ & 3 & $\mathrm{NO}_{2}$ & $>10$ & 0.190 & $>52.6$ \\
\hline $16 a$ & $\mathrm{H}$ & 2 & $\mathrm{H}$ & $>10$ & 0.027 & $>370.4$ \\
\hline $16 b$ & $\mathrm{H}$ & 3 & $\mathrm{H}$ & $>10$ & 8.990 & 1.11 \\
\hline $16 c$ & $3-F$ & 2 & $\mathrm{H}$ & $>10$ & 0.046 & $>217.4$ \\
\hline 16d & $3-F$ & 3 & $\mathrm{H}$ & 3.7 & 0.240 & 15.4 \\
\hline $16 e$ & $4-\mathrm{F}$ & 2 & $\mathrm{H}$ & $>10$ & 0.089 & $>112.3$ \\
\hline $16 f$ & $4-\mathrm{F}$ & 3 & $\mathrm{H}$ & $>10$ & 0.940 & $>10.6$ \\
\hline Celecoxib & & & & 3.84 & 0.061 & $>63$ \\
\hline
\end{tabular}

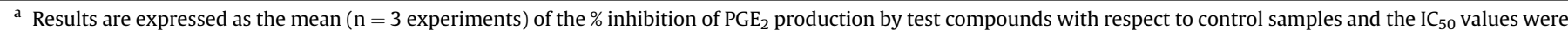
calculated by GraphPad Instat program; data fit was obtained using the sigmoidal dose-response equation (variable slope) (GraphPad software).

b In vitro COX-2 Selectivity Index $\left[\mathrm{IC}_{50}(\mathrm{COX}-1) / \mathrm{IC}_{50}(\mathrm{COX}-2)\right]$. 
Table 16

Dose-response results of compounds $15 \mathbf{a}-\mathbf{e}, \mathbf{1 6} \mathbf{a}-\mathbf{d}$, and Celecoxib in the Acetic Acid Writhing Test. ${ }^{\mathrm{a}}$

\begin{tabular}{lllll}
\hline Compd. & n mice & dose per os $(\mathrm{mg} / \mathrm{kg})$ & no. writhes & Writhes reduction $(\%)$ \\
\hline Saline & 6 & & $32.4 \pm 1.9$ & - \\
15a & 10 & 10 & $21.2 \pm 3.0 \wedge$ & 35 \\
& 8 & 20 & $15.5 \pm 3.6^{*}$ & 53 \\
15b & 9 & 10 & $29.4 \pm 3.0$ & 9 \\
& 10 & 20 & $21.2 \pm 3.0^{*}$ & 35 \\
& 8 & 40 & $26.8 \pm 3.2 \wedge$ & 17 \\
15c & 8 & 10 & $32.5 \pm 3.7$ & 0 \\
& 8 & 20 & $30.3 \pm 2.1$ & 6 \\
& 8 & 40 & $25.3 \pm 3.6^{*}$ & 22 \\
15e & 8 & 3 & $28.5 \pm 3.2$ & 12 \\
& 8 & 10 & $19.1 \pm 2.7^{*}$ & 41 \\
& 8 & 20 & $15.2 \pm 3.3^{*}$ & 53 \\
16a & 8 & 10 & $21.2 \pm 3.0^{*}$ & 35 \\
& 8 & 20 & $15.5 \pm 3.6^{*}$ & 52 \\
16b & 9 & 10 & $29.7 \pm 3.4$ & 8 \\
& 9 & 20 & $22.3 \pm 2.5^{*}$ & 31 \\
& 7 & 40 & $21.5 \pm 2.3^{*}$ & 34 \\
16c & 8 & 10 & $29.4 \pm 3.0$ & 9 \\
& 8 & 20 & $26.8 \pm 3.2 \wedge$ & 17 \\
& 8 & 40 & $17.3 \pm 3.5^{*}$ & 47 \\
16e & 7 & 10 & $31.3 \pm 2.7$ & 3 \\
& 8 & 20 & $27.9 \pm 3.6$ & 14 \\
& 8 & 40 & $18.1 \pm 3.1^{*}$ & 44 \\
Celecoxib & 10 & 1 & $25.6 \pm 3.1^{*}$ & 21 \\
& 11 & 3 & $15.4 \pm 2.5^{*}$ & 52 \\
& 15 & 10 & $11.3 \pm 2.9^{*}$ & 65 \\
\hline
\end{tabular}

${ }^{a}$ Each value represents the mean of at least seven mice: $(\wedge) \mathrm{P}<0.05$.

$(*) \mathrm{P}<0.01$ in comparison with CMC treated group.

confirming what previously shown in terms of dependence of the activity with side chain length. Experiments with ODQ confirmed the vasorelaxing effects were due to the NO release. COX-2 inhibition was assessed ex vivo by the HWB assay for compounds 15e and 16e [66]. Concentration-response curves for inhibition of COX1 and COX-2 in HWB showed compound 15e and its derivative 16e inhibited LPS induced $\mathrm{PGE}_{2}$ generation (COX-2 assay) in a concentration-dependent fashion with $\mathrm{IC}_{50}$ values respectively of 0.64 and $0.44 \mu \mathrm{M}$. Compounds 15e and 16e also showed comparable $\mathrm{IC}_{80}$ values (respectively 2.26 and $2.31 \mu \mathrm{M}$ ). These results pointed out that $15 \mathbf{e}$ and its metabolite $16 \mathbf{e}$ gave a comparable and potent inhibitory effect on COX-2 activity in HWB. Furthermore, 15e and 16e inhibited platelet COX-1 activity in a concentrationdependent fashion; 16e was slightly more potent $\left(\mathrm{IC}_{50}=20.0\right.$; $\left.\mathrm{IC}_{80}=37.14\right)$ in COX-1 inhibition than 15e $\left(\mathrm{IC}_{50}=31.24\right.$; $\mathrm{IC}_{80}=63.3$ ). Thus, both compounds were proved to be selective, being 50 -fold more potent toward COX-2 than COX-1 at $\mathrm{IC}_{50}$. Compounds 15a-f, and corresponding hydroxylated derivatives were evaluated in vivo, both in the writhing test and in the carrageenan-induced inflammatory pain model [66]. In the writhing test the minimal dose able to revert the painful condition was $10 \mathrm{mg} / \mathrm{kg}$ po for 15a, 15e and 16a, $20 \mathrm{mg} / \mathrm{kg}$ for $\mathbf{1 5 b}, \mathbf{1 6 b}, 40 \mathrm{mg} /$ $\mathrm{kg}$ for $\mathbf{1 5 c}$ and $\mathbf{1 6 e}$ (Table 16). In the carrageenan inflammatory pain model all the tested molecules were effective in the range between 40 and $20 \mathrm{mg} / \mathrm{kg}$ po, at $120 \mathrm{~min}$, and a significant paw edema decrease was observed 60 min after the administration for all the investigated compounds (Table 17) [67]. At the higher tested dose, the antihyperalgesic activity lasted up to $120 \mathrm{~min}$ for all the compounds, except for $\mathbf{1 5 a}$ and $\mathbf{1 5 b}$.

The incubation of $\mathbf{1 5 e}$ in rat plasma was followed by a negligible formation of nitrites and nitrates $(3.2 \pm 0.7 \mu \mathrm{M}$ and $0.24 \pm 0.24 \mu \mathrm{M}$, respectively, at $120 \mathrm{~min}$ ) while the corresponding experiment with naproxcinod showed a massive formation of nitrate [70]. The incubation of 15e in liver homogenate was followed by a slow and time-dependent production of nitrites and nitrates; after $120 \mathrm{~min}$ of incubation, the recorded concentrations were $4.6 \pm 0.5 \mu \mathrm{M}$ and $26.9 \pm 3.4 \mu \mathrm{M}$, respectively. Naproxcinod showed a more rapid accumulation of larger amounts of these metabolites $(28.0 \pm 6.0 \mu \mathrm{M}$ of nitrites and $340.1 \pm 5.0 \mu \mathrm{M}$ of nitrates, at $120 \mathrm{~min}$ ) [70]. Therefore, 15e exhibited the feature of "NO-reservoir", stable in plasma and slowly converted to NO by the cell metabolism (liver, vascular smooth muscle, endothelium, etc.). The 15e NO-releasing properties were confirmed by the endothelium-independent vasorelaxing effects evoked in aortic rings of normotensive rats; these effects were antagonized by ODC. In order to determine the NO generation in vivo and its possible effects on the progression of systolic blood pressure (SBP), 15e ( $20 \mathrm{mg} / \mathrm{kg} /$ day) was chronically administered to young male spontaneous hypertensive rats (SHRs) [70] The effect of the metabolite 16e was studied as well. The coxib-associated CV adverse effects are increased when other CV disorders are already present; therefore, 15e effect was studied when chronically

Table 17

Effect of 15a-c, 16a-c, 16e and Celecoxib on hyperalgesia and edema induced by carrageenan in the Rat Paw Pressure Test.

\begin{tabular}{|c|c|c|c|c|c|c|c|c|}
\hline \multicolumn{9}{|c|}{ paw pressure (g) } \\
\hline \multirow{2}{*}{$\begin{array}{l}\text { pretreatment } \\
\text { ip }\end{array}$} & \multirow[t]{2}{*}{ Compd. } & \multirow[t]{2}{*}{ dose $\mathrm{mg} / \mathrm{kg}$} & \multirow[t]{2}{*}{ before treatment } & \multicolumn{3}{|c|}{ after treatment } & \multicolumn{2}{|l|}{ Paw volume $(\mathrm{mL})$} \\
\hline & & & & $30 \mathrm{~min}$ & $60 \mathrm{~min}$ & $120 \mathrm{~min}$ & before treatment & $60 \mathrm{~min}$ \\
\hline Saline & CMC & - & $62.6 \pm 2.4$ & $61.5 \pm 3.1$ & $60.2 \pm 3.3$ & $62.9 \pm 3.5$ & $1.46 \pm 0.05$ & $1.42 \pm 0.07$ \\
\hline Carrageenan & CMC & & $31.4 \pm 3.4$ & $34.8 \pm 3.0$ & $33.9 \pm 3.7$ & $31.4 \pm 3.7$ & $1.47 \pm 0.07$ & $2.48 \pm 0.06$ \\
\hline Carrageenan & $15 a$ & 20 & $33.9 \pm 3.1$ & $54.2 \pm 3.1 *$ & $55.3 \pm 3.5^{*}$ & $48.7 \pm 3.7 \wedge$ & $1.31 \pm 0.09$ & $1.45 \pm 0.10 *$ \\
\hline Carrageenan & $15 b$ & 10 & $34.1 \pm 2.7$ & $55.1 \pm 4.7 *$ & $52.6 \pm 4.0^{*}$ & $48.3 \pm 5.2 \wedge$ & $1.49 \pm 0.08$ & $1.87 \pm 0.07 *$ \\
\hline Carrageenan & & 20 & $32.0 \pm 3.5$ & $56.8 \pm 3.9 *$ & $49.2 \pm 4.6^{*}$ & $43.8 \pm 4.5 \wedge$ & $1.53 \pm 0.08$ & $1.92 \pm 0.08 *$ \\
\hline Carrageenan & $15 c$ & 20 & $34.6 \pm 3.0$ & $43.9 \pm 3.1 \wedge$ & $40.7 \pm 3.0$ & $35.2 \pm 3.5$ & $1.58 \pm 0.08$ & $2.16 \pm 0.09 \wedge$ \\
\hline Carrageenan & & 40 & $31.6 \pm 2.7$ & $47.3 \pm 4.2 *$ & $41.0 \pm 4.4$ & $34.3 \pm 4.1$ & $1.55 \pm 0.09$ & $2.08 \pm 0.07 *$ \\
\hline Carrageenan & $16 a$ & 20 & $32.7 \pm 3.7$ & $44.6 \pm 4.0 \wedge$ & $46.9 \pm 4.2 \wedge$ & $38.8 \pm 3.5$ & $1.54 \pm 0.06$ & $2.19 \pm 0.07 \wedge$ \\
\hline Carrageenan & & 40 & $35.2 \pm 3.1$ & $49.5 \pm 3.8^{*}$ & $42.5 \pm 4.1$ & $35.3 \pm 3.8$ & $1.48 \pm 0.07$ & $2.10 \pm 0.08 *$ \\
\hline Carrageenan & $16 b$ & 20 & $33.8 \pm 3.8$ & $52.9 \pm 3.6^{*}$ & $50.3 \pm 2.9 *$ & $46.6 \pm 3.1 \wedge$ & $1.47 \pm 0.05$ & $1.86 \pm 0.04 *$ \\
\hline Carrageenan & $16 c$ & 20 & $32.7 \pm 3.9$ & $46.9 \pm 3.8 \wedge$ & $48.6 \pm 3.5 \wedge$ & $37.2 \pm 3.9$ & $1.55 \pm 0.08$ & $2.46 \pm 0.08$ \\
\hline Carrageenan & & 40 & $33.5 \pm 3.9$ & $51.4 \pm 3.0 *$ & $45.3 \pm 4.4 \wedge$ & $39.5 \pm 4.0$ & $1.49 \pm 0.09$ & $2.12 \pm 0.06 \wedge$ \\
\hline Carrageenan & $16 e$ & 20 & $32.5 \pm 3.4$ & $46.8 \pm 3.7 *$ & $38.7 \pm 3.3$ & $38.3 \pm 3.9$ & $1.57 \pm 0.07$ & $2.01 \pm 0.09 *$ \\
\hline Carrageenan & & 40 & $30.5 \pm 3.5$ & $57.2 \pm 4.6 *$ & $58.3 \pm 4.5^{*}$ & $47.6 \pm 4.4 \wedge$ & $1.55 \pm 0.09$ & $1.95 \pm 0.08 *$ \\
\hline Carrageenan & Celecoxib & 3 & $31.7 \pm 2.7$ & $44.3 \pm 3.8 *$ & $41.6 \pm 3.2$ & $40.7 \pm 2.6$ & $1.59 \pm 0.08$ & $2.35 \pm 0.07$ \\
\hline Carrageenan & & 10 & $33.5 \pm 2.6$ & $52.9 \pm 3.1 *$ & $48.3 \pm 3.4^{*}$ & $39.8 \pm 3.1$ & $1.50 \pm 0.05$ & $1.45 \pm 0.06 *$ \\
\hline
\end{tabular}

$(\wedge) \mathrm{P}<0.05,(*) \mathrm{P}<0.01$ versus the carrageenan/saline-treated group. 
administered to SHRs, a suitable experimental model of heavy alteration of the CV function. Indeed, in young SHRs, an age-related progression of blood pressure is always observed and highly selective COX2 inhibitors, such as rofecoxib, accelerate and worsen it. After one month of pharmacological treatments of SHRs, serum concentrations of nitrites and nitrates were measured [70]. Though, treatment with 16e did not influence the levels of plasma nitrites and nitrates, in the 15e-treated animals the concentration of nitrites was not significantly changed but a significant increase in nitrates concentration of was observed. In the Langendorffperfused isolated hearts of vehicle-treated SHRs, the coronary flow was like that recorded in normotensive animals. The coronary flow in SHR rats treated with 15e was significantly increased while the one of 16e-treated animals was not significantly changed. The SBP development in 15e-treated SHRs was completely equivalent to that of vehicle treated SHRs, while treatment with 16e (devoid of NO releasing properties) did not accelerate the age-related increase of SBP in young SHRs. Overall this indicates that the NO-releasing property of 15e can significantly improve the overall CV function and thus is a useful complementary aspect for coxibs.

\section{Conclusions}

Cystic fibrosis, a life-shortening disease due to mutations in CFTR ion channel, among other complications can lead to severe lung deficiency, characterized by chronic respiratory disease and lung damage with persistent and exaggerated inflammation that gives rise to irreversible airway destruction leading to morbidity and mortality in CF patients. Therapies targeting the root cause of CF have been recently developed, and results from several clinical trials are available. These therapies are based on compounds that in principle could reverse the CFTR molecular defect, preventing the CF progression. However, the available results are not completely satisfying and at least two of these therapies must be simultaneously carried out in order to obtain relevant clinical results. On the other hand, the treatment of the dysfunctional inflammatory response underling the irreversible airway destruction and fibrosis in CF has been proved difficult with t-NSAIDs or steroidal antiinflammatory drugs. Though several evidences suggest that COX-2 could be a remarkable target for treating inflammation in $\mathrm{CF}$, the efficacy of coxibs has not been investigated yet, probably owing to the related side effects. Nitric oxide plays an essential role in a variety of biological processes in the lung. In addition, NO can stabilize CFTR and correct its disfunction by protein nitrosylation. Despite this physiological importance, low concentrations of NO were found in CF patients, and therapeutic interventions aiming to correct the nitric oxide deficiency in CF patients are investigated at the present. There is a growing interest in the class of bioavailable and stable nitrosothiols and corresponding precursors as a novel class of corrector therapies for CF. Herein we discussed how a suitable NO-releasing moiety endowed with appropriate releasing rates can be conjugated to a coxib, according to a strategy aimed at both improving drug effectiveness and moderating those side effects linked to the mechanism of action of the native drug. The efforts aimed at overcoming pharmacokinetics issues related to bioavailability and stability of the compounds have been discussed along with the characteristics of the products that are suitable candidates for further development. Taking together the topics discussed above it appears that the best performing compounds (11a in the amide and 15e in the ether classes) can be good candidates to treat $\mathrm{CF}$ according to a new and promising approach.

\section{Declaration of competing interest}

The authors declare that they have no known competing financial interests or personal relationships that could have appeared to influence the work reported in this paper.

\section{Acknowledgments}

This work has been supported by Italian Ministry of Education, Universities and Research - Dipartimenti di Eccellenza - L. 232/2016.

\section{References}

[1] L. Csanády, P. Vergani, D.C. Gadsby, Structure, gating, and regulation of the CFTR anion channel, Physiol. Rev. 99 (2019) 707-738, https://doi.org/10.1152/ physrev.00007.2018.

[2] V. Saint-Criq, M.A. Gray, Role of CFTR in epithelial physiology, Cell. Mol. Life Sci. 74 (2017) 93-115, https://doi.org/10.1007/s00018-016-2391-y.

[3] B. Klimova, K. Kuca, M. Novotny, P. Maresova, Cystic fibrosis revisited - a review study, Med. Chem. 13 (2017) 102-109, https://doi.org/10.2174/ 1573406412666160608113235.

[4] M.D. Amaral, C.M. Farinha, Rescuing mutant CFTR: a multi-task approach to a better outcome in treating cystic fibrosis, Curr. Pharmaceut. Des. 19 (2013) 3497-3508, https://doi.org/10.2174/13816128113199990318.

[5] B. Garcia, P.A. Flume, Pulmonary complications of cystic fibrosis, Semin. Respir. Crit. Care Med. 40 (2019) 804-809, https://doi.org/10.1055/s-00391697639.

[6] J.S. Elborn, Cystic fibrosis, Lancet 388 (2016) 2519-2531, https://doi.org/ 10.1016/S0140-6736(16)00576-6.

[7] C. Castellani, B.M. Assael, Cystic fibrosis: a clinical view, Cell. Mol. Life Sci. 74 (2017) 129-140, https://doi.org/10.1007/s00018-016-2393-9.

[8] J.F. Collawn, S. Matalon, CFTR and lung homeostasis, Am. J. Physiol. Lung Cell Mol. Physiol. 307 (2014) L917-L923, https://doi.org/10.1152/ ajplung.00326.2014.

[9] A.M. Cantin, D. Hartl, M.W. Konstan, J.F. Chmiel, Inflammation in cystic fibrosis lung disease: pathogenesis and therapy, J. Cyst. Fibros. 14 (2015) 419-430, https://doi.org/10.1016/j.jcf.2015.03.003.

[10] E.A. Roesch, D.P. Nichols, J.F. Chmiel, Inflammation in cystic fibrosis: an update, Pediatr. Pulmonol. 53 (2018) S30-S50, https://doi.org/10.1002/ ppul.24129.

[11] S.C. Ranganathan, G.L. Hall, P.D. Sly, S.M. Stick, T.A. Douglas, Australian respiratory early surveillance team for cystic fibrosis (AREST-CF), early lung disease in infants and preschool children with cystic fibrosis. What have we learned and what should we do about it? Am. J. Respir. Crit. Care Med. 195 (2017) 1567-1575, https://doi.org/10.1164/rccm.201606-1107CI.

[12] S.T. Montgomery, M.A. Mall, A. Kicic, S.M. Stick, C.F. Arest, Hypoxia and sterile inflammation in cystic fibrosis airways: mechanisms and potential therapies, Eur. Respir. J. 49 (2017), https://doi.org/10.1183/13993003.00903-2016.

[13] A. Balázs, M.A. Mall, Mucus obstruction and inflammation in early cystic fibrosis lung disease: emerging role of the IL-1 signaling pathway, Pediatr. Pulmonol. 54 (Suppl 3) (2019) S5-S12, https://doi.org/10.1002/ppul.24462.

[14] M. Cockx, M. Gouwy, J. Van Damme, S. Struyf, Chemoattractants and cytokines in primary ciliary dyskinesia and cystic fibrosis: key players in chronic respiratory diseases, Cell. Mol. Immunol. 15 (2018) 312-323, https://doi.org/ 10.1038/cmi.2017.118.

[15] Z.M. Sellers, B. Illek, M.F. Figueira, G. Hari, N.S. Joo, E. Sibley, J. Souza-Menezes, M.M. Morales, H. Fischer, J.J. Wine, Impaired PGE2-stimulated $\mathrm{Cl}-$ and $\mathrm{HCO}_{3}-$ secretion contributes to cystic fibrosis airway disease, PloS One 12 (2017), e0189894, https://doi.org/10.1371/journal.pone.0189894.

[16] A. Bannon, S.-D. Zhang, B.C. Schock, M. Ennis, Cystic fibrosis from laboratory to bedside: the role of A20 in NF- $\kappa$ B-mediated inflammation, Med. Princ. Pract. 24 (2015) 301-310, https://doi.org/10.1159/000381423.

[17] K. Czerska, A. Sobczynska-Tomaszewska, D. Sands, A. Nowakowska, D. Bak, K. Wertheim, J. Poznanski, J. Zielenski, A. Norek, J. Bal, Prostaglandin-endoperoxide synthase genes COX1 and COX2 - novel modifiers of disease severity in cystic fibrosis patients, J. Appl. Genet. 51 (2010) 323-330, https://doi.org/ 10.1007/BF03208862.

[18] N. Rieber, A. Hector, M. Carevic, D. Hartl, Current concepts of immune dysregulation in cystic fibrosis, Int. J. Biochem. Cell Biol. 52 (2014) 108-112, https://doi.org/10.1016/j.biocel.2014.01.017.

[19] P.J. Mogayzel, E.T. Naureckas, K.A. Robinson, G. Mueller, D. Hadjiliadis, J.B. Hoag, L. Lubsch, L. Hazle, K. Sabadosa, B. Marshall, Pulmonary clinical practice guidelines committee, cystic fibrosis pulmonary guidelines. Chronic medications for maintenance of lung health, Am. J. Respir. Crit. Care Med. 187 (2013) 680-689, https://doi.org/10.1164/rccm.201207-1160oe.

[20] L.C. Lands, S. Stanojevic, Oral non-steroidal anti-inflammatory drug therapy for lung disease in cystic fibrosis, Cochrane Database Syst. Rev. (2013) CD001505, https://doi.org/10.1002/14651858.CD001505.pub3.

[21] L.C. Lands, N. Dauletbaev, High-dose ibuprofen in cystic fibrosis, Pharmaceuticals (Basel) 3 (2010) 2213-2224, https://doi.org/10.3390/ph3072213.

[22] I. Tegeder, J. Pfeilschifter, G. Geisslinger, Cyclooxygenase-independent actions of cyclooxygenase inhibitors, Faseb. J. 15 (2001) 2057-2072, https://doi.org/ 10.1096/fj.01-0390rev.

[23] J. Li, Y.-Y. Xiang, L. Ye, L.-C. Tsui, J.F. Macdonald, J. Hu, W.-Y. Lu, Nonsteroidal anti-inflammatory drugs upregulate function of wild-type and mutant CFTR, Eur. Respir. J. 32 (2008) 334-343, https://doi.org/10.1183/ 
09031936.00168007

[24] M. Gentzsch, M.A. Mall, Ion channel modulators in cystic fibrosis, Chest 154 (2018) 383-393, https://doi.org/10.1016/j.chest.2018.04.036.

[25] M. Mijnders, B. Kleizen, I. Braakman, Correcting CFTR folding defects by smallmolecule correctors to cure cystic fibrosis, Curr. Opin. Pharmacol. 34 (2017) 83-90, https://doi.org/10.1016/j.coph.2017.09.014.

[26] K.-Y. Jih, W.-Y. Lin, Y. Sohma, T.-C. Hwang, CFTR potentiators: from bench to bedside, Curr. Opin. Pharmacol. 34 (2017) 98-104, https://doi.org/10.1016/ j.coph.2017.09.015.

[27] K. Kuk, J.L. Taylor-Cousar, Lumacaftor and ivacaftor in the management of patients with cystic fibrosis: current evidence and future prospects, Ther. Adv. Respir. Dis. 9 (2015) 313-326, https://doi.org/10.1177/1753465815601934.

[28] M.W. Konstan, E.F. McKone, R.B. Moss, G. Marigowda, S. Tian, D. Waltz, X. Huang, B. Lubarsky, J. Rubin, S.J. Millar, D.J. Pasta, N. Mayer-Hamblett, C.H. Goss, W. Morgan, G.S. Sawicki, Assessment of safety and efficacy of longterm treatment with combination lumacaftor and ivacaftor therapy in patients with cystic fibrosis homozygous for the F508del-CFTR mutation (PROGRESS): a phase 3, extension study, Lancet Respir Med 5 (2017) 107-118, https://doi.org/10.1016/S2213-2600(16)30427-1.

[29] M.A. Sala, M. Jain, Tezacaftor for the treatment of cystic fibrosis, Expet Rev.

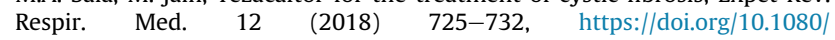
17476348.2018.1507741.

[30] J.L. Taylor-Cousar, A. Munck, E.F. McKone, C.K. van der Ent, A. Moeller, C. Simard, L.T. Wang, E.P. Ingenito, C. McKee, Y. Lu, J. Lekstrom-Himes, J.S. Elborn, Tezacaftor-Ivacaftor in patients with cystic fibrosis homozygous for Phe508del, N. Engl. J. Med. 377 (2017) 2013-2023, https://doi.org/10.1056/ NEJMoa1709846.

[31] P.G. Middleton, M.A. Mall, P. Dřevínek, L.C. Lands, E.F. McKone, D. Polineni, B.W. Ramsey, J.L. Taylor-Cousar, E. Tullis, F. Vermeulen, G. Marigowda, C.M. McKee, S.M. Moskowitz, N. Nair, J. Savage, C. Simard, S. Tian, D. Waltz, F. Xuan, S.M. Rowe, R. Jain, VX17-445-102 study group, ElexacaftorTezacaftor-Ivacaftor for cystic fibrosis with a single Phe508del allele, N. Engl. J. Med. 381 (2019) 1809-1819, https://doi.org/10.1056/ NEJMoa1908639.

[32] H.G.M. Heijerman, E.F. McKone, D.G. Downey, E. Van Braeckel, S.M. Rowe, E. Tullis, M.A. Mall, J.J. Welter, B.W. Ramsey, C.M. McKee, G. Marigowda, S.M. Moskowitz, D. Waltz, P.R. Sosnay, C. Simard, N. Ahluwalia, F. Xuan, Y. Zhang, J.L. Taylor-Cousar, K.S. McCoy, VX17-445-103 Trial Group, Efficacy and safety of the elexacaftor plus tezacaftor plus ivacaftor combination regimen in people with cystic fibrosis homozygous for the F508del mutation: a double-blind, randomised, phase 3 trial, Lancet 394 (2019) 1940-1948, https://doi.org/10.1016/S0140-6736(19)32597-8.

[33] D. Keating, G. Marigowda, L. Burr, C. Daines, M.A. Mall, E.F. McKone, B.W. Ramsey, S.M. Rowe, L.A. Sass, E. Tullis, C.M. McKee, S.M. Moskowitz, S. Robertson, J. Savage, C. Simard, F. Van Goor, D. Waltz, F. Xuan, T. Young, J.L. Taylor-Cousar, VX16-445-001 study group, VX-445-Tezacaftor-Ivacaftor in patients with cystic fibrosis and one or two Phe508del alleles, N. Engl. J. Med. 379 (2018) 1612-1620, https://doi.org/10.1056/NEJMoa1807120.

[34] H. Li, E. Pesce, D.N. Sheppard, A.K. Singh, N. Pedemonte, Therapeutic approaches to CFTR dysfunction: from discovery to drug development, J. Cyst. Fibros. 17 (2018) S14-S21, https://doi.org/10.1016/j.jcf.2017.08.013.

[35] F.L.M. Ricciardolo, P.J. Sterk, B. Gaston, G. Folkerts, Nitric oxide in health and disease of the respiratory system, Physiol. Rev. 84 (2004) 731-765, https:// doi.org/10.1152/physrev.00034.2003.

[36] I. Korten, M. Liechti, F. Singer, G. Hafen, I. Rochat, P. Anagnostopoulou, D. Müller-Suter, J. Usemann, A. Moeller, U. Frey, P. Latzin, C. Casaulta, SCILD and BILD study group, Lower exhaled nitric oxide in infants with Cystic Fibrosis compared to healthy controls, J. Cyst. Fibros. 17 (2018) 105-108, https://doi.org/10.1016/j.jcf.2017.05.005.

[37] M. Maniscalco, M. Sofia, G. Pelaia, Nitric oxide in upper airways inflammatory diseases, Inflamm. Res. 56 (2007) 58-69, https://doi.org/10.1007/s00011006-6111-1.

[38] M. Antosova, D. Mokra, L. Pepucha, J. Plevkova, T. Buday, M. Sterusky, A. Bencova, Physiology of nitric oxide in the respiratory system, Physiol. Res. 66 (2017) S159-S172, https://doi.org/10.33549/physiolres.933673.

[39] K.M. de Winter-de Groot, C.K. van der Ent, Nitric oxide in cystic fibrosis, J. Cyst. Fibros. 4 (Suppl 2) (2005) 25-29, https://doi.org/10.1016/j.jcf.2005.05.008.

[40] H. Grasemann, F. Ratjen, Nitric oxide and L-arginine deficiency in cystic fibrosis, Curr. Pharmaceut. Des. 18 (2012) 726-736, https://doi.org/10.2174/ 138161212799315911.

[41] L. Bentur, M. Gur, M. Ashkenazi, G. Livnat-Levanon, M. Mizrahi, A. Tal, A. Ghaffari, Y. Geffen, M. Aviram, O. Efrati, Pilot study to test inhaled nitric oxide in cystic fibrosis patients with refractory Mycobacterium abscessus lung infection, J. Cyst. Fibros. (2019), https://doi.org/10.1016/j.jcf.2019.05.002.

[42] O. Soren, A. Rineh, D.G. Silva, Y. Cai, R.P. Howlin, R.N. Allan, M. Feelisch, J.C. Davies, G.J. Connett, S.N. Faust, M.J. Kelso, J.S. Webb, Cephalosporin nitric oxide-donor prodrug DEA-C3D disperses biofilms formed by clinical cystic fibrosis isolates of Pseudomonas aeruginosa, J. Antimicrob. Chemother. 75 (2020) 117-125, https://doi.org/10.1093/jac/dkz378.

[43] F. Fabrizi, F. Mincione, T. Somma, G. Scozzafava, F. Galassi, E. Masini, F. Impagnatiello, C.T. Supuran, A new approach to antiglaucoma drugs: carbonic anhydrase inhibitors with or without NO donating moieties. Mechanism of action and preliminary pharmacology, J. Enzym. Inhib. Med. Chem. 27 (2012) 138-147, https://doi.org/10.3109/14756366.2011.597749.

[44] F. Mincione, F. Benedini, S. Biondi, A. Cecchi, C. Temperini, G. Formicola,
I. Pacileo, A. Scozzafava, E. Masini, C.T. Supuran, Synthesis and crystallographic analysis of new sulfonamides incorporating NO-donating moieties with potent antiglaucoma action, Bioorg. Med. Chem. Lett 21 (2011) 3216-3221, https://doi.org/10.1016/j.bmcl.2011.04.046.

[45] R.M. Steele, F. Benedini, S. Biondi, V. Borghi, L. Carzaniga, F. Impagnatiello, D. Miglietta, W.K.M. Chong, R. Rajapakse, A. Cecchi, C. Temperini, C.T. Supuran, Nitric oxide-donating carbonic anhydrase inhibitors for the treatment of open-angle glaucoma, Bioorg. Med. Chem. Lett 19 (2009) 6565-6570, https:// doi.org/10.1016/j.bmcl.2009.10.036.

[46] M.J.R. Ahonen, J.M. Dorrier, M.H. Schoenfisch, Antibiofilm efficacy of nitric oxide-releasing alginates against cystic fibrosis bacterial pathogens, ACS Infect. Dis. 5 (2019) 1327-1335, https://doi.org/10.1021/acsinfecdis.9b00016.

[47] M.J.R. Ahonen, D.J. Suchyta, H. Zhu, M.H. Schoenfisch, Nitric oxide-releasing alginates, Biomacromolecules 19 (2018) 1189-1197, https://doi.org/ 10.1021/acs.biomac.8b00063.

[48] D.T. Hess, A. Matsumoto, S.-O. Kim, H.E. Marshall, J.S. Stamler, Protein Snitrosylation: purview and parameters, Nat. Rev. Mol. Cell Biol. 6 (2005) 150-166, https://doi.org/10.1038/nrm1569.

[49] N.V. Marozkina, B. Gaston, Nitrogen chemistry and lung physiology, Annu. Rev. Physiol. 77 (2015) 431-452, https://doi.org/10.1146/annurev-physiol021113-170352.

[50] P. Anand, J.S. Stamler, Enzymatic mechanisms regulating protein S-nitrosylation: implications in health and disease, J. Mol. Med. 90 (2012) 233-244, https://doi.org/10.1007/s00109-012-0878-z.

[51] H. Grasemann, B. Gaston, K. Fang, K. Paul, F. Ratjen, Decreased levels of nitrosothiols in the lower airways of patients with cystic fibrosis and normal pulmonary function, J. Pediatr. 135 (1999) 770-772, https://doi.org/10.1016/ s0022-3476(99)70101-0.

[52] K. Zaman, D. Bennett, M. Fraser-Butler, Z. Greenberg, P. Getsy, A. Sattar, L. Smith, D. Corey, F. Sun, J. Hunt, S.J. Lewis, B. Gaston, S-Nitrosothiols, Increases cystic fibrosis transmembrane regulator expression and maturation in the cell surface, Biochem. Biophys. Res. Commun. 443 (2014) 1257-1262, https://doi.org/10.1016/j.bbrc.2013.12.130.

[53] A.H. Snyder, M.E. McPherson, J.F. Hunt, M. Johnson, J.S. Stamler, B. Gaston, Acute effects of aerosolized S-nitrosoglutathione in cystic fibrosis, Am. J. Respir. Crit. Care Med. 165 (2002) 922-926, https://doi.org/10.1164/ ajrccm.165.7.2105032.

[54] L. Chen, R.P. Patel, X. Teng, C.A. Bosworth, J.R. Lancaster, S. Matalon, Mechanisms of cystic fibrosis transmembrane conductance regulator activation by Snitrosoglutathione, J. Biol. Chem. 281 (2006) 9190-9199, https://doi.org/ 10.1074/jbc.M513231200.

[55] K. Zaman, J. Knight, F. Hussain, R. Cao, S.K. Estabrooks, G. Altawallbeh, K. Holloway, A. Jafri, V. Sawczak, Y. Li, P. Getsy, F. Sun, T. Raffay, C. Cotton, J.L. Brodsky, A. Periasamy, S.J. Lewis, B. Gaston, S-Nitrosylation of, CHIP enhances F508Del-CFTR maturation, Am. J. Respir. Cell Mol. Biol. 61 (2019) 765-775, https://doi.org/10.1165/rcmb.2018-03140C.

[56] G. García-Rayado, M. Navarro, A. Lanas, NSAID induced gastrointestinal damage and designing GI-sparing NSAIDs, Expet Rev. Clin. Pharmacol. 11 (2018) 1031-1043, https://doi.org/10.1080/17512433.2018.1516143.

[57] W. Kiefer, G. Dannhardt, Novel insights and therapeutical applications in the field of inhibitors of COX-2, Curr. Med. Chem. 11 (2004) 3147-3161, https:// doi.org/10.2174/0929867043363668.

[58] M.D. Ferrer, C. Busquets-Cortés, X. Capó, S. Tejada, J.A. Tur, A. Pons, A. Sureda, Cyclooxygenase-2 inhibitors as a therapeutic target in inflammatory diseases, Curr. Med. Chem. 26 (2019) 3225-3241, https://doi.org/10.2174/ 0929867325666180514112124.

[59] J.-M. Dogné, J. Hanson, C. Supuran, D. Pratico, Coxibs and cardiovascular sideeffects: from light to shadow, Curr. Pharmaceut. Des. 12 (2006) 971-975, https://doi.org/10.2174/138161206776055949.

[60] C. Patrono, Cardiovascular effects of cyclooxygenase-2 inhibitors: a mechanistic and clinical perspective, Br. J. Clin. Pharmacol. 82 (2016) 957-964, https://doi.org/10.1111/bcp.13048.

[61] S. Tacconelli, A. Bruno, R. Grande, P. Ballerini, P. Patrignani, Nonsteroidal antiinflammatory drugs and cardiovascular safety - translating pharmacological data into clinical readouts, Expet Opin. Drug Saf. 16 (2017) 791-807, https:// doi.org/10.1080/14740338.2017.1338272.

[62] T.J. Schnitzer, A. Kivitz, H. Frayssinet, B. Duquesroix, Efficacy and safety of naproxcinod in the treatment of patients with osteoarthritis of the knee: a 13week prospective, randomized, multicenter study, Osteoarthritis Cartilage 18 (2010) 629-639, https://doi.org/10.1016/j.joca.2009.12.013.

[63] M. Biava, G.C. Porretta, G. Poce, S. Supino, S. Forli, M. Rovini, A. Cappelli, F. Manetti, M. Botta, L. Sautebin, A. Rossi, C. Pergola, C. Ghelardini, E. Vivoli, F. Makovec, P. Anzellotti, P. Patrignani, M. Anzini, Cyclooxygenase-2 inhibitors. 1,5-diarylpyrrol-3-acetic esters with enhanced inhibitory activity toward cyclooxygenase- 2 and improved cyclooxygenase-2/cyclooxygenase-1 selectivity, J. Med. Chem. 50 (2007) 5403-5411, https://doi.org/10.1021/ jm0707525.

[64] M. Anzini, M. Rovini, A. Cappelli, S. Vomero, F. Manetti, M. Botta, L. Sautebin, A. Rossi, C. Pergola, C. Ghelardini, M. Norcini, A. Giordani, F. Makovec, P. Anzellotti, P. Patrignani, M. Biava, Synthesis, biological evaluation, and enzyme docking simulations of 1,5-diarylpyrrole-3-alkoxyethyl ethers as selective cyclooxygenase-2 inhibitors endowed with anti-inflammatory and antinociceptive activity, J. Med. Chem. 51 (2008) 4476-4481, https://doi.org/ $10.1021 /$ jm800084s.

[65] M. Biava, G.C. Porretta, G. Poce, C. Battilocchio, F. Manetti, M. Botta, S. Forli, 
L. Sautebin, A. Rossi, C. Pergola, C. Ghelardini, N. Galeotti, F. Makovec, A. Giordani, P. Anzellotti, P. Patrignani, M. Anzini, Novel ester and acid derivatives of the 1,5-diarylpyrrole scaffold as anti-inflammatory and analgesic agents. Synthesis and in vitro and in vivo biological evaluation, J. Med. Chem. 53 (2010) 723-733, https://doi.org/10.1021/jm901269y.

[66] M. Biava, G.C. Porretta, G. Poce, C. Battilocchio, S. Alfonso, M. Rovini, S. Valenti, G. Giorgi, V. Calderone, A. Martelli, L. Testai, L. Sautebin, A. Rossi, G. Papa, C. Ghelardini, L. Di Cesare Mannelli, A. Giordani, P. Anzellotti, A. Bruno, P. Patrignani, M. Anzini, Novel analgesic/anti-inflammatory agents: diarylpyrrole acetic esters endowed with nitric oxide releasing properties, J. Med. Chem. 54 (2011) 7759-7771, https://doi.org/10.1021/jm200715n.

[67] M. Anzini, A. Di Capua, S. Valenti, S. Brogi, M. Rovini, G. Giuliani, A. Cappelli, S. Vomero, L. Chiasserini, A. Sega, G. Poce, G. Giorgi, V. Calderone, A Martelli, L. Testai, L. Sautebin, A. Rossi, S. Pace, C. Ghelardini, L. Di Cesare Mannelli, V. Benetti, A. Giordani, P. Anzellotti, M. Dovizio, P. Patrignani, M. Biava, Novel analgesic/anti-inflammatory agents: 1,5-diarylpyrrole nitrooxyalkyl ethers and related compounds as cyclooxygenase- 2 inhibiting nitric oxide donors, J. Med. Chem. 56 (2013) 3191-3206, https://doi.org/10.1021/jm301370e.

[68] S. Consalvi, G. Poce, R. Ragno, M. Sabatino, C. La Motta, S. Sartini, V. Calderone, A. Martelli, C. Ghelardini, L. Di Cesare Mannelli, M. Biava, A series of COX-2 inhibitors endowed with NO-releasing properties: synthesis, biological evaluation, and docking analysis, ChemMedChem 11 (2016) 1804-1811, https:// doi.org/10.1002/cmdc.201600086.

[69] M. Biava, C. Battilocchio, G. Poce, S. Alfonso, S. Consalvi, G.C. Porretta, S. Schenone, V. Calderone, A. Martelli, L. Testai, C. Ghelardini, L. Di Cesare Mannelli, L. Sautebin, A. Rossi, A. Giordani, P. Patrignani, M. Anzini, Improving the solubility of a new class of antiinflammatory pharmacodynamic hybrids, that release nitric oxide and inhibit cycloxygenase-2 isoenzyme, Eur. J. Med. Chem. 58 (2012) 287-298, https://doi.org/10.1016/j.ejmech.2012.10.014.

[70] A. Martelli, L. Testai, M. Anzini, A. Cappelli, A. Di Capua, M. Biava, G. Poce, S. Consalvi, A. Giordani, G. Caselli, L. Rovati, C. Ghelardini, P. Patrignani, L. Sautebin, M.C. Breschi, V. Calderone, The novel anti-inflammatory agent VA694, endowed with both NO-releasing and COX2-selective inhibiting properties, exhibits NO-mediated positive effects on blood pressure, coronary flow and endothelium in an experimental model of hypertension and endothelial dysfunction, Pharmacol. Res. 78 (2013) 1-9, https://doi.org/10.1016/ j.phrs.2013.09.008.
[71] M. Biava, C. Battilocchio, G. Poce, S. Alfonso, S. Consalvi, A. Di Capua, V. Calderone, A. Martelli, L. Testai, L. Sautebin, A. Rossi, C. Ghelardini, L. Di Cesare Mannelli, A. Giordani, S. Persiani, M. Colovic, M. Dovizio, P. Patrignani, M. Anzini, Enhancing the pharmacodynamic profile of a class of selective COX2 inhibiting nitric oxide donors, Bioorg. Med. Chem. 22 (2014) 772-786, https://doi.org/10.1016/j.bmc.2013.12.008.

[72] A. Bhardwaj, S.N. Batchu, J. Kaur, Z. Huang, J.M. Seubert, E.E. Knaus, Cardiovascular properties of a nitric oxide releasing rofecoxib analogue: beneficial anti-hypertensive activity and enhanced recovery in an ischemic reperfusion injury model, ChemMedChem 7 (2012) 1365-1368, https://doi.org/10.1002/ cmdc.201200234.

[73] K.R.A. Abdellatif, A. Moawad, E.E. Knaus, Synthesis of new 1-(4methane(amino)sulfonylphenyl)-5-(4-substituted-aminomethylphenyl)-3trifluoromethyl-1H-pyrazoles: a search for novel nitric oxide donor antiinflammatory agents, Bioorg. Med. Chem. Lett 24 (2014) 5015-5021, https://doi.org/10.1016/j.bmcl.2014.09.024.

[74] M.A. Chowdhury, K.R.A. Abdellatif, Y. Dong, G. Yu, Z. Huang, M. Rahman, D. Das, C.A. Velázquez, M.R. Suresh, E.E. Knaus, Celecoxib analogs possessing a $\mathrm{N}$-(4-nitrooxybutyl)piperidin-4-yl or N-(4-nitrooxybutyl)-1,2,3,6tetrahydropyridin-4-yl nitric oxide donor moiety: synthesis, biological evaluation and nitric oxide release studies, Bioorg. Med. Chem. Lett 20 (2010) 1324-1329, https://doi.org/10.1016/j.bmcl.2010.01.014.

[75] M.M. Muley, E. Krustev, J.J. McDougall, Preclinical assessment of inflammatory pain, CNS Neurosci. Ther. 22 (2016) 88-101, https://doi.org/10.1111/ cns.12486,

[76] K.R. Patil, U.B. Mahajan, B.S. Unger, S.N. Goyal, S. Belemkar, S.J. Surana, S. Ojha, C.R. Patil, Animal models of inflammation for screening of anti-inflammatory drugs: implications for the discovery and development of phytopharmaceuticals, Int. J. Mol. Sci. 20 (2019), https://doi.org/10.3390/ijms20184367.

[77] H. Li, X. Liu, H. Cui, Y.-R. Chen, A.J. Cardounel, J.L. Zweier, Characterization of the mechanism of cytochrome $\mathrm{P} 450$ reductase-cytochrome $\mathrm{P} 450$-mediated nitric oxide and nitrosothiol generation from organic nitrates, J. Biol. Chem. 281 (2006) 12546-12554, https://doi.org/10.1074/jbc.M511803200.

[78] M. Govoni, S. Casagrande, R. Maucci, V. Chiroli, P. Tocchetti, In vitro metabolism of (nitrooxy)butyl ester nitric oxide-releasing compounds: comparison with glyceryl trinitrate, J. Pharmacol. Exp. Therapeut. 317 (2006) 752-761, https://doi.org/10.1124/jpet.105.097469. 